Poeschel, F. (2016), "Raising the mobility of thirdcountry nationals in the EU. Effects from naturalisation and long-term resident", OECD Social, Employment and Migration Working Papers, No. 187, OECD Publishing, Paris.

http://dx.doi.org/10.1787/5j|wxbvfdkr3-en

OECD Social, Employment and Migration Working Papers No. 187

\title{
Raising the mobility of third- country nationals in the EU. Effects from naturalisation and long-term resident status
}

\author{
Friedrich Poeschel
}

JEL Classification: F22, J61, K37 
Organisation de Coopération et de Développement Économiques

Organisation for Economic Co-operation and Development

02-Jun-2016

DIRECTORATE FOR EMPLOYMENT, LABOUR AND SOCIAL AFFAIRS

English - Or. English

EMPLOYMENT, LABOUR AND SOCIAL AFFAIRS COMMITTEE

Cancels \& replaces the same document of 04 May 2016

Raising the mobility of third-country nationals in the EU. Effects from naturalisation and long-term resident status

Friedrich Poeschel (OECD)

\section{JEL Classification:}

F22, J61, K37

This paper is part of the joint project between the Directorate General for Migration and Home Affairs of the European Commission and the OECD's Directorate for Employment, Labour and Social Affairs on "Review of Labour Migration Policy in Europe".

This document has been produced with the financial assistance of the European Union. The views expressed herein can in no way be taken to reflect the official opinion of the European Union.

Grant: HOME/2013/EIFX/CA/002 / 30-CE-0615920/00-38 (DI130895)

A previous version of this paper (DELSA/ELSA/MI(2015)5) was presented and discussed at the OECD working party on migration in June 2015.

Authorised for publication by Stefano Scarpetta, Director, Directorate for Employment, Labour and Social Affairs, OECD.

www.oecd.org/els/workingpapers

JT03397249

Complete document available on OLIS in its original format

This document and any map included herein are without prejudice to the status of or sovereignty over any territory, to the delimitation of international frontiers and boundaries and to the name of any territory, city or area. 


\title{
DIRECTORATE FOR EMPLOYMENT, LABOUR AND SOCIAL AFFAIRS
}

\author{
www.oecd.org/els
}

\section{OECD SOCIAL, EMPLOYMENT AND MIGRATION WORKING PAPERS}

\author{
www.oecd.org/els/workingpapers
}

OECD Working Papers should not be reported as representing the official views of the OECD nor of its member countries nor of the members of the European Union. The opinions expressed and arguments employed are those of the author(s).

Working Papers describe preliminary results or research in progress by the author(s) and are published to stimulate discussion on a broad range of issues on which the OECD works. Comments on Working Papers are welcomed, and may be sent to the Directorate for Employment, Labour and Social Affairs OECD, 2 rue André-Pascal, 75775 Paris Cedex 16, France.

This series is designed to make available to a wider readership selected labour market, social policy and migration studies prepared for use within the OECD. Authorship is usually collective, but principal writers are named. The papers are generally available only in their original language - English or French with a summary in the other.

This document and any map included herein are without prejudice to the status of or sovereignty over any territory, to the delimitation of international frontiers and boundaries and to the name of any territory, city or area.

\section{Applications for permission to reproduce or translate all or part of this material should be made to:}

\author{
Head of Publications Service \\ OECD \\ 2, rue André-Pascal \\ 75775 Paris, CEDEX 16 \\ France
}

Copyright OECD 2016 


\begin{abstract}
This paper is part of the joint project between the Directorate General for Migration and Home Affairs of the European Commission and the OECD's Directorate for Employment, Labour and Social Affairs on "Review of Labour Migration Policy in Europe".

This document has been produced with the financial assistance of the European Union. The views expressed herein can in no way be taken to reflect the official opinion of the European Union.

Grant: HOME/2013/EIFX/CA/002 / 30-CE-0615920/00-38 (DI130895)

A previous version of this paper (DELSA/ELSA/MI(2015)5) was presented and discussed at the OECD working party on migration in June 2015.

The functioning of labour markets in the European Union can benefit if third-country nationals become more mobile between EU member states. Using micro data from the EU Labour Force Survey, this paper measures their mobility and investigates whether it is raised by naturalisation or long-term resident status. While third-country nationals are overall less mobile than EU citizens, tertiary-educated persons appear equally mobile in both groups. Raising the mobility of all third-country nationals to the level of EU citizens would add at least 25000 mobile persons. Causal effects on mobility from long-term resident status and naturalisation are identified through a difference-in-difference approach. Results suggest that long-term resident status increases the mobility of third-country nationals by $2 \%-6 \%$. To avoid selection bias in the results for naturalisation, this paper draws on a natural experiment: following the accession of Central and Eastern European countries to the EU, all their citizens indiscriminately obtained the rights of EU citizens. The evidence suggests that those who were already living in other EU countries became more mobile as a result. These findings highlight that intra-EU mobility of third-country nationals depends on their rights to reside and work in other EU countries.
\end{abstract}




\section{TABLE OF CONTENTS}

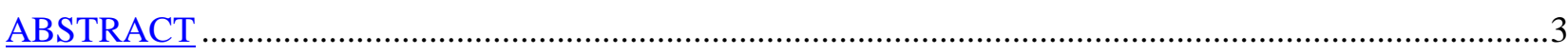

RAISING THE MOBILITY OF THIRD-COUNTRY NATIONALS IN THE EU. EFFECTS FROM NATURALISATION AND LONG-TERM RESIDENT STATUS.............................................................

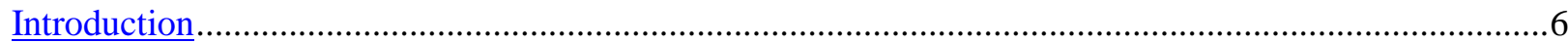

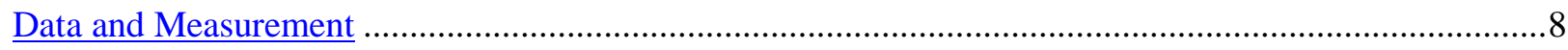

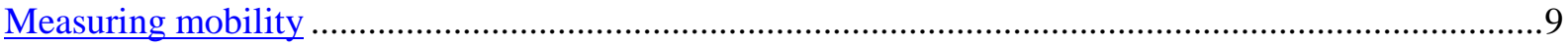

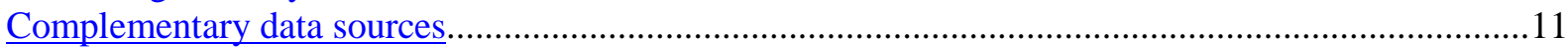

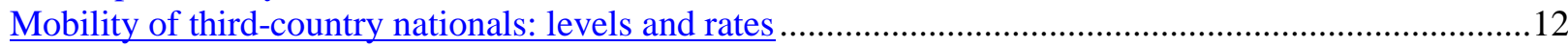

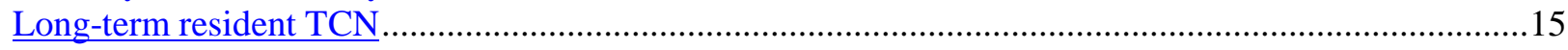

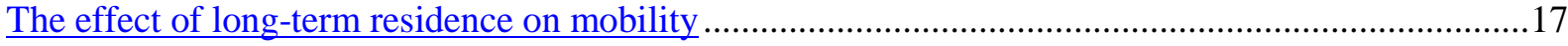

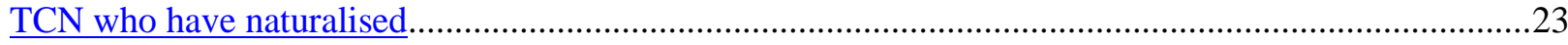

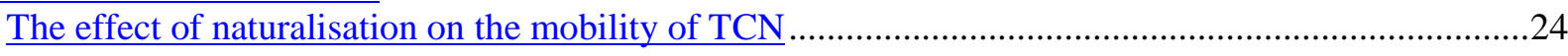

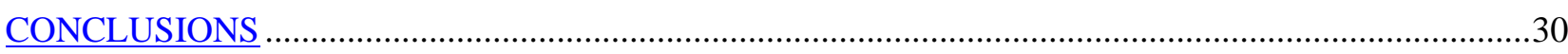

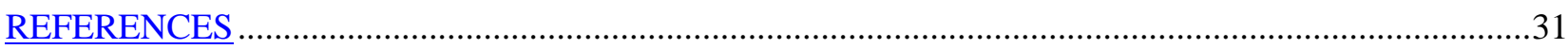

ANNEX A: KEY VARIABLES IN THE EU LABOUR FORCE SURVEY ……....................................33

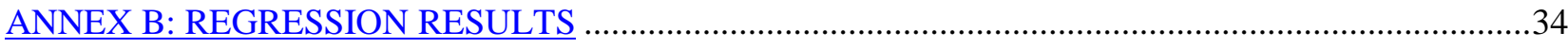

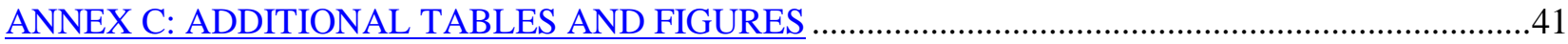

\section{Tables}

Table 1. Sample sizes in the EU Labour Force Survey, 2009-2012 …..............................................

Table 2. Descriptive statistics on third-country nationals in the EU and on EU citizens.....................11

Table 3. Third-country nationals by group of nationalities, 2008-2012 ..........................................13

Table 4. Estimated effects of long-term residence on mobility of TCN , 2009-2012 …....................20

Table A.1. Variables in the EU Labour Force Survey.........................................................................33

Table B.1. $\quad$ Estimation of a model with individual covariates, 2011/2012 .....................................34

Table B.2. $\quad$ Estimation of a model with individual covariates and fixed effects, 2011/2012 ..............35

Table B.3. Estimation of a model with individual covariates and clustered S.E.s, 2011/2012 ..........36

Table B.4. Estimation of a model with individual covariates, 2011/2012 ......................................37

Table B.5. $\quad$ Estimation of a model with individual covariates and fixed effects, 2011/2012..............38

Table B.6. Estimation of a model with individual covariates, 2011/2012 ......................................39

Table B.7. Estimation of a model with individual covariates and fixed effects, $2011 / 2012 \ldots \ldots \ldots \ldots . . .40$

Table C.1. Highly educated third-country nationals by group of nationalities, 2008-2012 .............41

Table C.2. $\quad$ TCN who are eligible for long-term residence by group of nationality, 2008-2012 ........43 


\section{Figures}

Figure 1. Mobility rates of third-country nationals and EU citizens, 2008-2012 ............................14

Figure 2. Holders of long-term resident permits by citizenship, selected nationalities, 2013 ..............16

Figure 3. TCN in the EU who are eligible for long-term residence, by country of residence, $2012 \ldots .17$

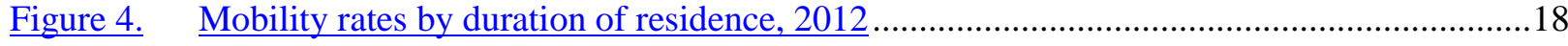

Figure 5. Mobility rates of treatment and control groups, 2011/2012 …......................................21

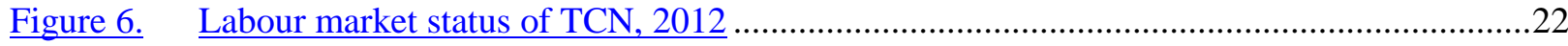

Figure 7. Naturalised EU citizens born outside the EU, 2008 ......................................................23

Figure 8. Naturalisations by previous nationality, selected countries, 2000-2012 …........................24

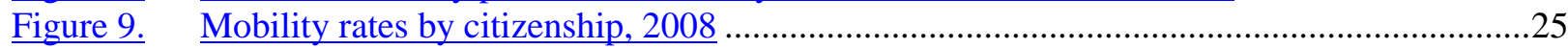

Figure 10. Mobility of NMS10 citizens in Austria, Belgium, Denmark and Germany, 2009-2012...26

Figure 11. Mobility rates of treatment and control groups, 2007-2012 …......................................28

Figure $\mathrm{C1} . \quad$ Coverage of long-term resident permits by EU member state, 2012 ...............................42

Figure C.2. Number of long-term residence permits by issuing EU member state, 2012 …..............43 


\section{RAISING THE MOBILITY OF THIRD-COUNTRY NATIONALS IN THE EU. EFFECTS FROM NATURALISATION AND LONG-TERM RESIDENT STATUS}

\section{Introduction}

1. While the European Union has brought an unprecedented freedom of movement to the citizens of EU member countries, citizens of non-EU countries - known as third-country nationals (TCN) - are in a very different situation when moving from one EU country to another, and especially when seeking work in another EU country. The freedom to choose one's place of residence and to take up employment anywhere in the EU does not carry over to TCN, and they can face an array of restrictions and conditions that vary greatly between EU member states. This paper focuses on TCN who become long-term residents or citizens of an EU country. It explores whether the lowering of mobility barriers that comes with such a change of status increases their mobility within the EU.

2. There are at least two reasons why it would be desirable if TCN who already reside in an EU member state could more easily move and take up employment in another EU member state. Firstly, this would contribute to a better functioning of the internal labour market of the EU: not only could unemployed TCN then go more easily where the jobs are, their mobility could also speed up labour market adjustment. Migrants might be especially mobile precisely because they have moved before - they are often not as settled in their current place of residence and the labour market opportunities that attracted many of them might attract them again.

3. There is evidence that immigrants often choose their location in response to labour market opportunities. Borjas (2001) finds that newly arriving immigrants in the United States choose to locate where their skills are most highly rewarded and that wage differences between regions disappear more quickly when immigration is high. Keeton and Newton (2005) report that immigrants in the United States tend to locate where strong growth in labour demand can be expected.

4. For a number of countries, it has been found that migrants are more likely to move in response to labour market opportunities than the native-born. Amuedo-Dorantes and De la Rica (2010) document for Spain that immigrants, more so than the native-born, choose locations where their skills give them high chances of employment. Åslund (2005) and Røed and Schøne (2012) respectively find for Sweden and Norway that immigrants respond more strongly to opportunities on the labour market than the native-born, also after their arrival; Cadena and Kovak (2013) report this for Mexican-born workers in the United States. Schündeln (2014) provides such evidence for Germany and estimates that the costs immigrants incur from moving amount to only $31 \%$ of the costs incurred by native-born.

5. This evidence suggests that the mobility of TCN in the EU could facilitate the adjustment of member countries' labour markets. Rapid labour market adjustment would not only reduce the incidence of unemployment and the losses from unfilled vacancies. It would also stabilise the European currency union: asymmetric developments among Eurozone countries, for example in real wages, cannot be offset by exchange rate movements, but may be alleviated by labour flows between countries (see Puhani, 2001 for a discussion). Finally, a study of migration in Finland by Sarvimäki, Uusitalo and Jantti (2010) indicates that migrants can accelerate structural change, as they are more likely to locate in cities and to take up the new professions created there. 
6. The benefits from thick-market effects, i.e. from market size, are the second reason why a greater mobility of TCN in the EU would be desirable. Participating in a large labour market rather than a small one can have several advantages. For one, adverse shocks to employment might hit a part of large markets, but affected workers can still find employment in other parts of the market. Next, economies of scale or positive spill-overs (e.g. word of mouth) can allow job seekers to find employment sooner. Further, certain jobs might be so rare that they can only be found in large markets, and workers who qualified for these jobs can thus find a better match in large markets (see Helsley and Strange, 1990); this appears particularly relevant for highly skilled workers.

7. Evidence for beneficial thick-market effects is likewise available for several countries. Analysing British data, Petrongolo and Pissarides (2006) conclude that unemployed job seekers find better paid jobs in larger markets, and while the job seekers could find a job more quickly, they also become more selective in larger markets, so that the duration of unemployment remains virtually the same. Using data from Italy, Di Addario (2011) finds that the size of the labour market has a positive effect on job seekers' probability to find employment. Based on data from the Netherlands, Kok (2014) reports a lower degree of mismatch in larger labour markets.

8. Because of thick-market effects, larger labour markets may appear more attractive to migrants, and especially to highly skilled migrants. Across many destinations for labour migrants, efforts are increasing to attract skilled migrants, to offer them favourable working conditions, and to thereby retain them. In the competition for highly skilled TCN, the vast set of possibilities in an EU-wide labour market could prove a crucial advantage over other attractive destinations.

9. Alongside likely benefits from higher mobility of TCN in the EU, there may also be drawbacks. ${ }^{1}$ National administrations in the EU might come to expect that TCN move on to other countries during economic downturns. Given this expectation, more TCN might be admitted during economic upturns than the country's labour market can accommodate beyond the short-run. Further, TCN might use greater opportunities for mobility to move to EU countries where they expect high welfare benefits.

10. The institutions of the European Union chose to address the situation of TCN in EU countries through a number of Directives. Alongside Directives targeting researchers and intra-company transfers, Directive 2003/109/EC turned to the situation of TCN who have legally and continuously resided in an EU member country for at least five years. ${ }^{2}$ Such long-term residents may be issued an EU long-term residence permit, valid for five years at least and automatically renewable. As regards the mobility of long-term resident TCN, the Directive formulated an ambitious principle: "[a person] who holds a long-term residence permit should be granted in that Member State a set of uniform rights which are as near as possible to those enjoyed by citizens of the European Union".

11. However, the articles of Directive 2003/109/EC allow for many exceptions from this principle. These exceptions appear very relevant: as documented in EMN (2013), a long list of restrictions and conditions on the mobility of TCN has remained in place. While not all of them are necessarily applied in practice, TCN who consider moving within the EU still face a bewildering variety of provisions that might render such endeavours impossible. As a result, many TCN might be prevented from taking up employment opportunities in other EU member states despite their status as long-term residents, many might be discouraged to search for such opportunities, and many might not migrate to the EU in the first place for fear of finding themselves stuck in one particular location.

1 The author thanks Marco Manacorda and Pawel Kaczmarczyk for raising these points.

2 Only one half of residence for the purpose of study is counted towards this minimum duration. Denmark, Ireland and the United Kingdom opted out of Directive 2003/109/EC. 
12. Given the persistence of such obstacles, it is all but clear whether Directive 2003/109/EC has had a significant positive effect on the mobility of TCN. Evaluating its effect empirically is complicated by the heterogeneity in restrictions and conditions for TCN across EU member states, as this very likely leads to a similar heterogeneity of any discernible effects. To still identify statistically significant effects, one would need international data of high-quality that include a large sample of mobile TCN. Instead, it is concluded in EMN (2013) that suitable data appear to be lacking, while national statistics prove limited and incomparable.

13. To make headway, this paper does not seek to directly evaluate the impact of Directive 2003/109/EC but takes a broader approach that can, indirectly, still produce insights about the Directive and more generally about the likely effects of lifting restrictions on the mobility of TCN. Alongside longterm resident TCN, the paper also focuses on those who used to be TCN but have become EU citizens though naturalisation at some point. As they then enjoy the same freedom of movement as any other EU citizen, their mobility should essentially be unconstrained (while it might still be affected by remaining constraints on family members). TCN who have naturalised thus provide a useful point of comparison somewhat simplistically, they could be regarded as TCN with the maximum freedom of movement that could be given to long-term residents.

14. Virtually no findings on the effect of long-term residence and naturalisation on cross-border mobility can be drawn from the research literature - it appears that this question has thus far not been addressed. Instead, some results on the mobility between jobs and sectors have been obtained: Bratsberg, Ragan and Nasir (2002) report that those who naturalise in the United States subsequently take up opportunities that become available with U.S. citizenship, such as jobs in the public sector. For France, Edo and Jarreau (2014) find that naturalisation leads to higher job mobility, especially to moves from occupations with low skill requirements to occupations with higher skill requirements. As a more general result from reduced barriers to mobility, Beine, Bourgeon and Bricongne (2013) provide evidence that the Schengen agreements and the currency union have led to greater mobility of workers within the EU.

15. The paper proceeds as follows. The next section discusses data sources and the measurement of key variables. The following section quantifies the mobility levels and rates of TCN in the EU. The paper then turns to an econometric investigation, using a difference-in-difference methodology to estimate the effect of long-term residence on the mobility of TCN. The analysis will be extended to the effect of naturalisation before some overall conclusions are offered.

\section{Data and Measurement}

16. A number of international data sets are employed in this paper, but primarily individual-level data from the EU Labour Force Survey for the years 2009 to 2012. This annual survey among households was assembled by Eurostat based on data collected in all EU member countries (except Croatia, which joined the EU in 2013), the EFTA countries (except Liechtenstein), Turkey and the Former Yugoslav Republic of Macedonia. Sample sizes vary considerably across countries; by consequence, statistics derived from these samples may be more reliable for some countries than for others. Despite such differences, EU Labour Force Survey data appear much more comparable between countries than data from national sources, thanks to the common Eurostat definitions employed in data collection.

17. For most analyses in this paper, all available data from EU countries are pooled, while one analysis uses pooled data from four EU countries. For both cases, Table 1 shows the number of available observations, separately for the entire sample and for the subsample of TCN. As nationals of EFTA countries enjoy free movement, they are not counted towards the subsample: the group of interest are TCN whose mobility within the EU might be constrained. By applying weights provided in the EU Labour Force Survey, observations are translated into numbers of individuals who share the characteristics associated 
with the observation. The marked increase in observations from Austria, Belgium, Denmark and Germany from 2011 to 2012 thus merely reflects an increase in sample sizes.

Table 1. Sample sizes in the EU Labour Force Survey, 2009-2012

\begin{tabular}{l|l|rrrr}
\hline & Observations & 2009 & 2010 & 2011 & 2012 \\
\hline \multirow{2}{*}{ EU 27 countries } & in total & 4229665 & 4538122 & 4294969 & 4598391 \\
& on TCN (withoutEFTA) & 105364 & 113575 & 113987 & 129939 \\
\hline Austria, Belgium, & in total & 458404 & 465417 & 465501 & 904085 \\
Denmark, Germany & on TCN (withoutEFTA) & 14715 & 15110 & 16659 & 34786 \\
\hline
\end{tabular}

Note: Observations from Croatia are unavailable for all years; observations from Malta are not available for 2012.

Source: $\quad$ EU Labour Force Survey (Eurostat).

18. The EU Labour Force Survey covers a range of demographic and work-related variables, notably age, sex, nationality, country of birth, marital status, the presence of children, educational attainment, occupation and labour force status. TCN are identified using the information on nationality; in some cases, analyses in this paper will further distinguish among TCN by their region of birth. These analyses do not include TCN who reside in Germany but were not born there, as information on their place of birth is not available. Cases of multiple citizenships are resolved in the data as follows. If the individual holds the citizenship of the current country of residence, this citizenship is recorded; otherwise, the citizenship of an EU member state is recorded if held by the individual; in any remaining case, the citizenship is recorded that the individual indicates first (see Eurostat, 2013). Nationality and other key variables discussed below are tabulated for TCN in Annex A. The tabulations also specify the proportion of missing values, which is very low for nationality.

19. For all individuals who were born outside of the country they are surveyed in, the EU Labour Force Survey records the elapsed duration of stay as years of residence in the current country of residence. This variable allows identifying those who qualify in all likelihood as long-term residents in their current country of residence, in so far as they were resident there each year for at least five consecutive years. According to Eurostat (2013), earlier years of residence in the same country are not counted if the individual has since then been resident elsewhere for at least one year. ${ }^{3}$

20. TCN for whom at least five consecutive years of residence are recorded can therefore be thought of as eligible for an EU long-term residence permit, with some caveats. Residence for the purpose of study counts only half towards the minimum duration, so that some are not eligible despite residence of five years or more, and irregular migrants are not eligible. These caveats would lead to an overestimate of those who are indeed eligible for EU long-term residence. On the other hand, TCN might have fulfilled the minimum residence duration in another EU country or in their current country of residence before they resided elsewhere for at least a year. Such cases would rather lead to an underestimate of the eligible TCN. In effect, the two biases will offset each other to some extent.

\section{Measuring mobility}

21. The measure of mobility employed in this paper draws on two questions included in the EU Labour Force Survey (see Eurostat, 2013). These questions ask respondents in which country they were residing one year before and in which country they work. The responses refer to individual countries, and a respondent can thus be counted as being mobile within the EU if the country indicated is a member of

3 It should further be noted that residence of less than one year is recorded as 01 , residence of more than one but less than two years as 02 , and so on. In particular, five years of residence corresponds to 06. 
the EU but not the same as the EU country that they reside in at the time of the survey. To be counted as mobile, it suffices to indicate another EU country either as the country of previous residence or as the current country of work. Individuals who are mobile according to both criteria are only once counted as mobile individuals.

22. Both variables used in the measurement of mobility come with caveats. The country of residence in the previous year is always missing in observations from Finland, Ireland, Malta and the Netherlands. As a result, 20\% of all observations from 2009 to 2012 have missing values (see Table A.3 in Annex A). For the country of work, almost none of the observations from this period are missing values (see Table A.4 in Annex A). However, it has to be kept in mind that the question does not apply to all those not in employment at the time of the survey, who account for $57 \%$ of the observations collected from 2009 to 2012 .

23. As surveyed respondents are only asked at one particular time of the year, short-term mobility might often escape this way of measuring mobility. For example, a respondent who has worked in another EU country for only a few months in the current year would not be counted as mobile, as long as the respondent did not live in another EU country in the previous year. In addition, a number of reasons can be envisaged why mobile individuals might often not register in surveys such as the EU Labour Force Survey, for example as result of a recent change of address or change of employer that make mobile individuals less susceptible to be successfully contacted by those administering the survey.

24. At the same time, one can expect this problem to be much less pronounced in the case of mobile $\mathrm{TCN}$ in the EU, as they are typically required to register with authorities and to maintain up-to-date contact details. For this reason, it is much more likely that the mobility of EU citizens is underestimated by the cases recorded in the EU Labour Force Survey, as they often do not register with authorities. Finally, the mobility that arises from TCN who reside in the EU without a legal status is likely severely underestimated. Individuals in such an irregular position might not only keep their whereabouts and contact details secret but might also refuse particularly often to participate in surveys.

25. Nevertheless, the various sources of bias - missing values in key variables, unobserved shortterm mobility and under-sampling of migrants - likely lead to substantial underestimation of the true scale of intra-EU mobility. However, since the same measurement is used throughout this paper, all measurements might well be affected in roughly the same way. Thus even if each individual measurement is an underestimate, the relative differences between measurements will still give a reliable indication of the true difference. By consequence, valid conclusions may be inferred from comparisons between imperfect measurements. Comparisons between the measured mobility of TCN and that of EU citizens might, however, constitute an exception because mobile European citizens might register less with authorities than TCN do, so that they are less likely to be recorded by the EU Labour Force Survey. 
DELSA/ELSA/WD/SEM(2016)13

Table 2. Descriptive statistics on third-country nationals in the EU and on EU citizens

\begin{tabular}{l|c|c|c|c|c}
\hline \multirow{2}{*}{ statistic } & \multicolumn{3}{|c|}{ TCN } & EU citizens \\
\cline { 2 - 6 } & 2009 & 2010 & 2011 & 2012 & 2012 \\
\hline average age & 32 & 33 & 33 & 33 & 41 \\
share of women (in \%) & 50 & 50 & 51 & 51 & 51 \\
share that is tertiary educated (in \%) & 15 & 15 & 18 & 18 & 18 \\
share with a medium-level of education (in \%) & 27 & 27 & 26 & 26 & 36 \\
employment rate (in \%) & 45 & 44 & 44 & 43 & 44 \\
unemployment rate (in \%) & 20 & 21 & 21 & 23 & 10 \\
share that is married (in \%) & 47 & 48 & 47 & 47 & 44 \\
share with a child present (in \%) & 40 & 41 & 40 & 40 & 31 \\
\hline
\end{tabular}

Note: Observations from Croatia are unavailable for all years; observations from Malta are not available for 2012.

Source: EU Labour Force Survey (Eurostat).

26. Beyond the tabulations in Annex A of the key variables discussed, Table 2 offers some descriptive statistics for TCN and EU citizens. As can be expected for data on stocks, the composition of the sampled TCN hardly seems to change over the years 2009 to 2012, with the exception that the share of tertiary educated individuals suddenly rises from 15\% to 18\% between 2010 and 2011. In the case of EU citizens, descriptive statistics are only reported for 2012 because the figures in earlier years hardly vary at all and never diverge by more than one percentage point from the 2012 figures. Table 2 shows some notable differences between sampled TCN and EU citizens: TCN are much younger on average, fewer of them have a medium level of education and their unemployment rate is double that of EU citizens. More TCN than EU citizens are married and share their household with a child.

\section{Complementary data sources}

27. A key variable missing from the EU Labour Force Survey is whether or not an individual acquired the recorded nationality through naturalisation. In 2008, however, the EU Labour Force Survey was extended by an ad-hoc module (AHM) that oversampled migrants and introduced a small number of additional questions specifically to explore the situation of migrants and their families. The AHM, documented in Eurostat (2010), notably offers information on whether migrants have naturalised, on their reasons for migration, restrictions on their labour market access, and the duration of their residence permit. While the latter two variables are affected by measurement issues, such issues might also affect the exact year of naturalisation, but probably not whether an individual naturalised or not (see Eurostat, 2010 for details).

28. The AHM includes close to 1.44 million observations, covering all EU member countries except Finland, Malta and Croatia. A total of 29348 observations are available on TCN, disregarding nationals of EFTA countries for the reasons mentioned above. Alongside the additional variables, the AHM also comprises the usual variables recorded in the EU Labour Force Survey. While fewer values are missing for years of residence in the AHM than in the EU Labour Force Survey of the following years $(0.7 \%$ compared to $2.9 \%$ after excluding EU citizens, see Table A.2 in Annex A), more values are missing for nationality (5.9\% compared to $1.7 \%$, see Table A.1). The frequency of missing values for country of residence one year before is about the same in both data sets (21.4\% compared to $20.5 \%$, see Table A.3). Country of work features almost no missing values, and is not applicable in $49 \%$ of the observations (compared to $57 \%$ in the EU Labour Force Survey, see Table A.4). 
29. While reliable stock data on naturalised individuals is thus available from the AHM, figures for the annual flow of naturalisations can be obtained from the OECD's International Migration Database (IMD). This data source unifies information supplied by a network of correspondents in OECD countries. As these figures thus derive from national sources, the underlying definitions might vary. By consequence, the comparability of these figures is limited across countries; yet such problems are much less likely to arise in comparisons over time.

30. Similarly, Eurostat assembles a data collection on residence permits (Resper) by drawing on national sources in EU member countries. From 2008, yearly information is available on the number of residence permits in each member state that were valid on December $31^{\text {st }}$, including the number of longterm residence permits issued under Directive 2003/109/EC that are valid on this day. Since all valid longterm residence permits are counted irrespectively of when they have been issued, these figures reflect the stock of long-term residents rather than the flow of newly issued long-term residence permits. These data also provide the sex, age, and citizenship of the TCN receiving the permit. However, comparisons with the EU Labour Force Survey, as explained below, suggest that long-term residents are only partially covered by the Resper data and that this degree of coverage varies considerably across countries. Therefore, the Resper data cannot serve as an alternative basis for the econometric analyses in this paper that draw on the EU Labour Force Survey.

\section{Mobility of third-country nationals: levels and rates}

31. In recent years, the number of TCN residing in the EU has climbed over the level of 19 million and stood at 19.1 million in 2012, according to the EU Labour Force Survey (see Table 3). By far the largest group is made up of the nationals of European countries that are not EU or EFTA members, such as Ukraine, Serbia and Albania. Throughout the period 2008-2012, this group alone accounted for about 35\% of all TCN, or 6.7 million in 2012. Nationals of African countries form the second largest group and reached 5 million in 2012, an increase of $14 \%$ over the level in 2008. The same growth is observed for the nationals from Asian countries without the Near Middle East - from 2.7 million in 2008, their number has grown to 3.2 million, making it the third largest group of TCN. This group has thus surpassed the nationals of South and Central American countries: in 2008, the latter were still the third largest group, but have since shrunk considerably to a level of 2.6 million. Comparatively small groups are made up by the nationals of EFTA countries (0.2 million in 2012), of countries in North America ( 0.5 million) and Australia and Oceania ( 0.2 million). Together, these three groups accounted for less than $5 \%$ of the TCN throughout the period 2008-2012. 
DELSA/ELSA/WD/SEM(2016)13

Table 3. Third-country nationals by group of nationalities, 2008-2012

in thousands

\begin{tabular}{lrrrrr}
\hline Group of nationalities & 2008 & 2009 & 2010 & 2011 & 2012 \\
\hline EFTAcountries & 200 & 206 & 211 & 202 & 214 \\
Europe without EU/EFTA & 6307 & 6438 & 6553 & 6638 & 6700 \\
Africa & 4349 & 4575 & 4759 & 4837 & 4967 \\
Near Middle East & 754 & 864 & 734 & 768 & 827 \\
Other Asia & 2715 & 2645 & 2753 & 2891 & 3166 \\
North America & 410 & 474 & 486 & 455 & 478 \\
South and Central America & 3180 & 3256 & 2981 & 3009 & 2582 \\
Australia and Oceania & 239 & 227 & 166 & 207 & 168 \\
\hline Total & 18155 & 18685 & 18643 & 19006 & 19101 \\
\hline
\end{tabular}

Note: The geographical delimitation is adopted from Eurostat.

Source: EU Labour Force Survey (Eurostat).

32. While $18 \%$ of the TCN (or 3.4 million individuals) were counted as highly educated in 2012, this share had still been 15\% (or 2.7 million) only in 2010 (see Table C.1 in the Annex). TCN from European countries (without EFTA) account for 35\% of all TCN over the period 2008-2012, but they do not make up more than a quarter of the highly educated TCN. By contrast, while nationals of EFTA countries, of countries in North America, Australia and Oceania together account for only 5\% of all TCN, they make up around $13 \%$ of the highly educated TCN throughout the period. This suggests that the composition of the highly educated TCN differs substantially from the composition of the TCN population. A comprehensive discussion of the situation of TCN can be found in OECD (2015).

33. The number of TCN residing in the EU amounts to millions, but the number of TCN who are mobile within the EU appears to reach only tens of thousands. Altogether, only 45000 mobile TCN were observed in 2012, using the measurement of mobility explained above. However, the number of mobile TCN appears to have risen substantially over the period 2008-2012, coming from a level of only 17000 in 2008. As the number of mobile TCN has thus risen much faster than the total number of TCN, the share of mobile TCN has increased considerably over this time: when the financial crisis struck in 2008, as few as $0.10 \%$ of the TCN were observed to be mobile, followed by $0.22 \%$ in $2009,0.16 \%$ in 2010 and $0.19 \%$ in 2011 before reaching $0.24 \%$ in 2012. This mildly rising tendency confirms the impression in EMN (2013) that the overall mobility of TCN appears to be growing.

34. Throughout the period 2008-2012, the largest groups of mobile TCN were those originating from Africa (accounting for 20-30\% of all mobile TCN), Europe without EU/EFTA countries (12-25\%), Asia without the Near and Middle East (7-30\%) and South and Central America (7-21\%). While the observed numbers of mobile TCN exhibit considerable variation over time, there is a tendency towards larger numbers of mobile TCN from South and Central America, while the numbers tend to shrink in the case of TCN from Asia without the Near and Middle East. In 2012, TCN from South and Central America were the third-largest group of mobile TCN (accounting for 21\%), after TCN from Africa and from Europe without EU/EFTA countries (accounting for 25\% each). TCN from these two regions also made up the largest groups of mobile TCN with a tertiary education, together accounting for close to $60 \%$ of mobile TCN in 2012. 
35. Mobility rates of TCN can be obtained as the ratio of observed mobile TCN to all TCN in the EU. Figure 1 depicts the mobility rates for TCN overall and for tertiary-educated TCN only, alongside corresponding mobility rates for EU citizens. Nationals of EFTA countries enjoy free-movement in the EU because of bilateral agreements, so that their mobility rates might be outliers that create a misleading average mobility of TCN. Therefore, neither numerators nor denominators of the mobility rates in Figure 1 include EFTA nationals. However, since EFTA nationals make up only small shares of (mobile) TCN in the EU, excluding them does not change mobility rates much.

Figure 1. Mobility rates of third-country nationals and EU citizens, 2008-2012

Share of individuals observed to be mobile between EU countries, in percent

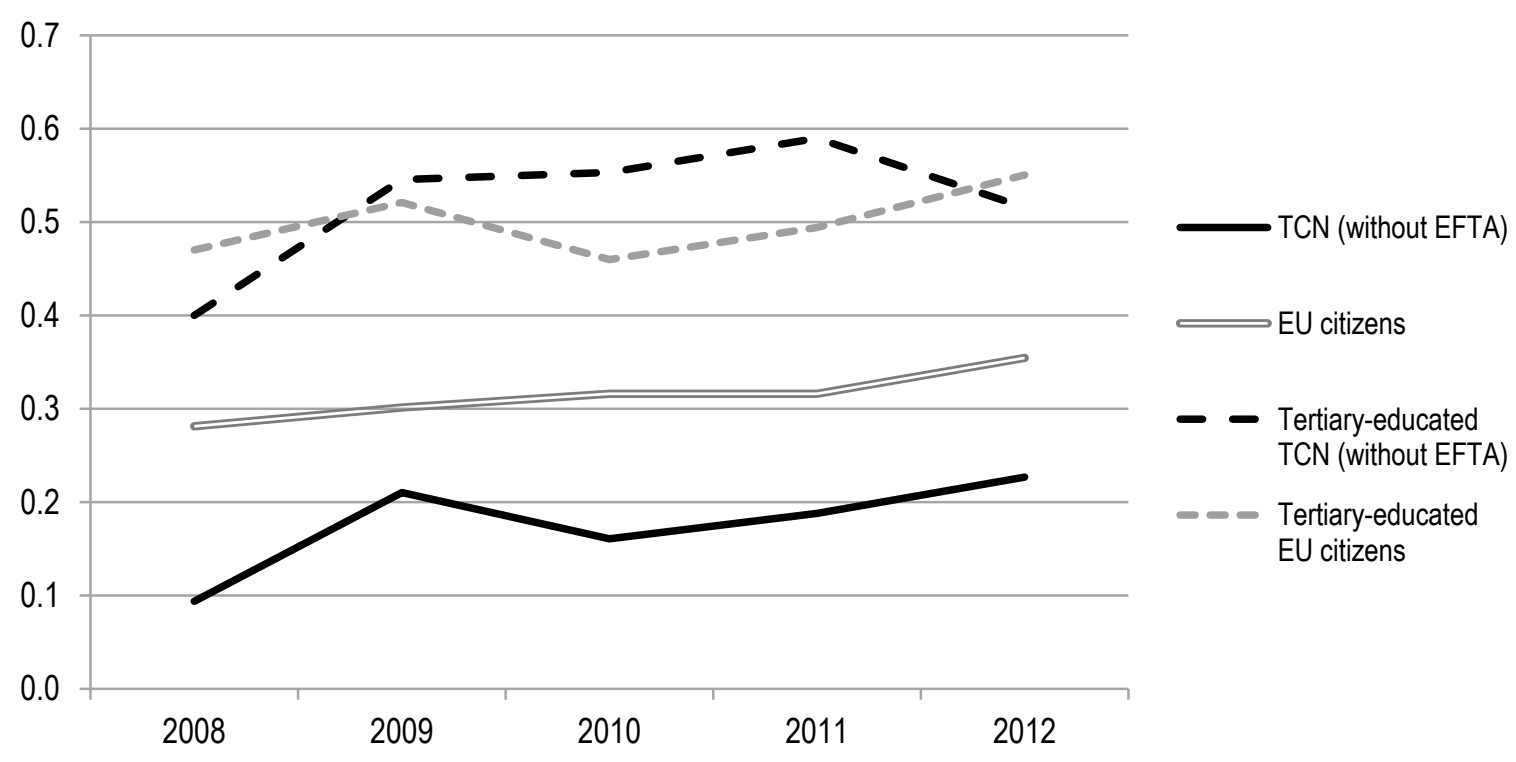

Note: $\quad$ Mobility involving Finland, Ireland, Malta or the Netherlands is only partially observed.

Source: OECD Secretariat calculations based on the EU Labour Force Survey (Eurostat).

36. As emphasised before, the mobility rates in Figure 1 almost certainly underestimate the true rates of mobility. Yet a number of informative comparisons can be made between the estimated mobility rates. The mobility rate of tertiary-educated TCN stands roughly at the same level as the mobility rate of tertiaryeducated EU citizens. Most recently, in 2012, the former slightly exceeded the latter. By contrast, the overall mobility rate of TCN is considerably lower than the corresponding rate for EU citizens: over the period 2008-2012, the rate for TCN amounted to between 33\% and 70\% of the rate for EU citizens. On average, the rate for TCN stood 0.14 percentage points below the rate for EU citizens.

37. Given findings in the literature that migrants' mobility reacts more strongly to labour market opportunities, it would not be surprising if TCN in the EU were significantly more mobile than EU citizens, in the absence of restrictions on mobility. Therefore, the proximity of the mobility rates of tertiary-educated TCN and tertiary-educated EU citizens does not necessarily imply that these two groups are equally free to move within the EU. Instead, it is well possible that tertiary-educated TCN face effective restrictions and that they would otherwise be more mobile. Yet it appears hard to guess the mobility rate that tertiary-educated TCN would exhibit if they could move freely. For the overall mobility rate of TCN, however, the overall mobility rate of EU citizens provides a benchmark: at least this level could be expected for the mobility rate of TCN if they did not face restrictions. If the mobility rate of TCN was accordingly raised by 0.14 percentage points, an additional 25000 mobile TCN would be observed in the EU per year. 
38. It is also worth noting from Figure 1 that the mobility rate of EU citizens has steadily climbed up over the period 2008-2012. This suggests that intra-EU mobility is not necessarily affected by cyclical fluctuations (while the destinations of migration flows might nevertheless change in line with cyclical developments - see Jauer et al., 2014). By contrast, the variation in the mobility rate of TCN seems to be affected by changing economic conditions, as large fluctuations in the crisis years 2008 and 2009 are followed by the return to a steady upward trend. Curiously, the mobility rate of tertiary-educated EU citizens exhibits exactly the same pattern. A somewhat different pattern emerges from the mobility rate of tertiary-educated TCN; this could reflect post-crisis changes in migration policies that might affect tertiaryeducated TCN differently.

39. Finally, both mobility rates for tertiary-educated individuals are much higher than the overall mobility rates (see Figure 1). In the period considered, the mobility rate of tertiary-educated TCN is almost three times as high as the overall rate. The gap between the corresponding rates for EU citizens is much smaller; the rate for tertiary-educated EU citizens exceeds the overall rate by two-thirds. That the gap is much larger for TCN than for EU citizens might arise from differential restrictions on mobility: while EU citizens enjoy free movement irrespectively of their education level, tertiary-educated TCN likely face fewer restrictions on their mobility than other TCN. Schemes for skilled migrants such as the EU Blue Card contain provisions granting participants greater freedom of movement within the EU, and tertiaryeducated TCNs qualify for national schemes in more EU countries than their less educated peers. One might otherwise expect equal gaps between rates, whether among TCN or among EU citizens. This is another reason to expect a higher overall mobility rate of TCN in the absence of restrictions.

\section{Long-term resident TCN}

40. The following sections will focus on long-term residents among the TCN in the EU, and will seek to establish whether long-term residence status raises mobility compared to other TCN. In general, observed mobility does not simply reflect an individual's or a family's wish to move - many such wishes might not be carried out because legal, financial or practical barriers constrain mobility. In so far as longterm residence status reduces such constraints on the mobility of TCN within the EU, it can be expected to have a positive effect on their observed mobility.

41. Directive 2003/109/EC specifies the conditions for the award of long-term residence status to TCN in the EU and specifies the rights associated with this status. According to the conditions, TCN will normally be entitled to long-term residence status after five years of legal and continuous residence in (the same) member countries of the EU, with the exception that period of residence for the purpose of study only count half. This condition does not preclude that member countries accord long-term residence status earlier. With regards to the rights of long-term residents, the principle set out in the Directive appears to be that they should enjoy approximately the same rights as EU citizens. At the same time, the Directive leaves EU member countries discretion to treat long-term residents differently in a number of ways, for example when granting labour market access.

42. As a result, long-term resident TCN seem to have a more favourable set of rights than other TCN, but less favourable than EU citizens. An EMN report on intra-EU mobility of TCN (see EMN, 2013) examines their legal situation in some detail. As opposed to other TCN, long-term resident TCN can move more easily together with their family and they do not need to first obtain a visa before applying for a residence permit in another EU country. But in contrast to EU citizens, they still need a residence permit in the first place, which might depend on evidence of sufficient financial resources and of suitable accommodation. Importantly, the labour market access of long-term resident TCN in another EU country may be restricted in many ways; according to EMN (2013), the majority of EU countries apply a labour market test when long-term resident TCN from another EU country seek access to the labour market. The 
EMN report further documents that long-term resident TCN face widely varying requirements across EU countries.

43. Based on residence permits, the number of long-term resident TCN in 2013 amounted to just over 7 million, holding either a long-term residence permit from an EU member state (4.3 million) or an EU long-term residence permit ( 2.8 million). Figure 2 gives numbers for the holders of long-term resident permits by nationality, highlighting the varying share of EU long-term residence permits. Many holders of long-term residence permits from Europe are citizens of Albania, the Ukraine, or of countries that emerged from former Yugoslavia. The largest groups from outside Europe are Moroccan, Chinese, Indian and Pakistani nationals.

Figure 2. Holders of long-term resident permits by citizenship, selected nationalities, 2013

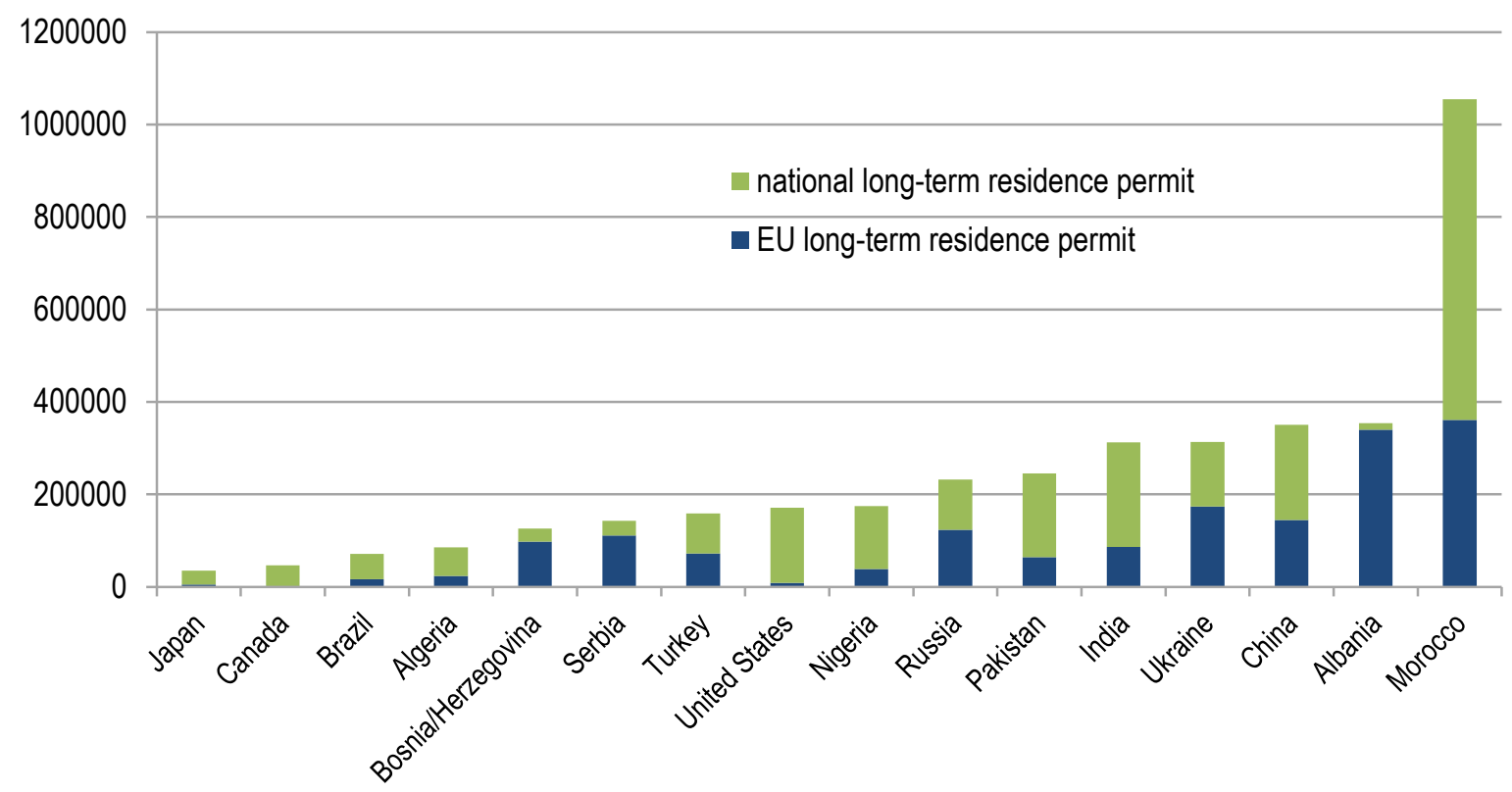

Note: $\quad$ Figures refer to all long-term resident permits valid on December $31^{\text {st }}, 2013$.

Source: Residence permit data collection (Eurostat).

44. However, figures on long-term residence permits only seem to capture a part of the actual longterm residents, as a comparison with figures on eligible TCN suggests. To obtain the latter, TCN with at least five years of residence in the same EU country are identified in the EU Labour Force Survey (see above for details); direct information on long-term residence status is not available in this Survey. Using 2012 data for comparability, Figure C.1 in the Annex shows that by far not all eligible TCN hold a longterm residence permit, either from an EU country or an EU long-term residence permit. In a number of EU countries, virtually none of the eligible TCN hold a long-term residence permit. In most of the other EU countries, less than $50 \%$ of those eligible appear to hold such a permit. In Latvia and Estonia, on the other hand, those holding a long-term residence permit well outnumber the eligible TCN. Overall, only about half of the eligible TCN in the EU hold a long-term residence permit. As Figure C.2 in the Annex shows, more than three quarters of these permits have been issued by only three countries: Spain (2.2 million), Italy (2.1 million) and the United Kingdom (1.5 million).

45. In the extreme case of Germany, close to 3 million eligible TCN are counted, but hardly any long-term residence permits. A first investigation of this discrepancy suggests that the Eurostat Resper figures are correct, but often do not count national long-term statuses that are more easily - if not even 
automatically - obtained by the long-term resident TCN. Circumstantial evidence further suggests that EU long-term residence permits might be taken up especially by TCN who intend to move to another EU member state for work, since national long-term statuses do not necessarily confer any such right.

46. In the light of these issues, the figures on eligible TCN appear to be the preferable approximation to the true number of long-term resident TCN. The distribution of eligible TCN over EU countries in 2012 is given in Figure 3. While the largest overall numbers of eligible TCN resided in Germany, Spain, Italy and France, it is worth noting that the largest number of the tertiary-educated among them can be found in the United Kingdom. The individual nationalities of eligible TCN cannot be determined from the available EU Labour Force Survey data, but Table C.3 in the Annex provides an overview by group of nationalities. Of more than 12 million eligible TCN in total, 4.4 million are nationals of European countries that are not members of the EU or EFTA; 3.5 million are nationals of African countries and 1.8 million are nationals of South and Central American countries.

Figure 3. TCN in the EU who are eligible for long-term residence, by country of residence, 2012

in thousands

\section{A. All eligible TCN}

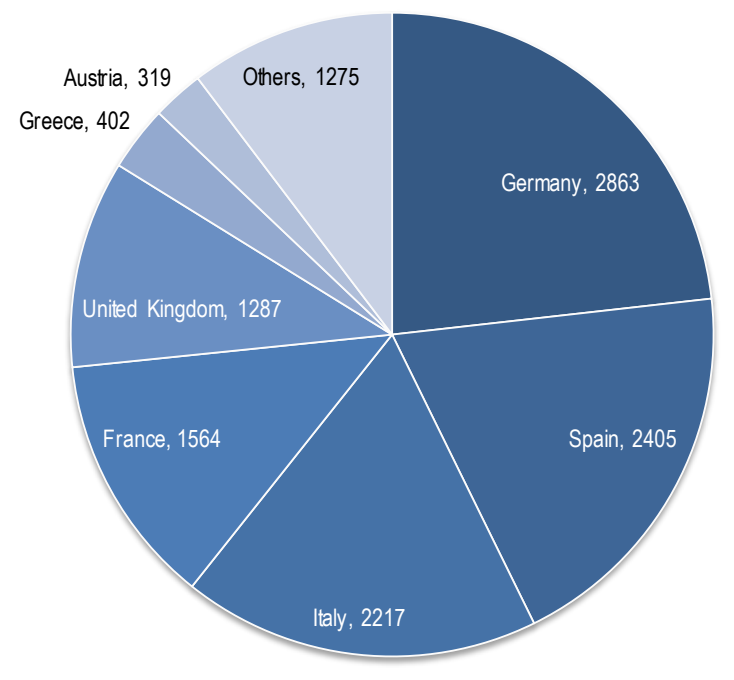

B. Eligible TCN with a tertiary education

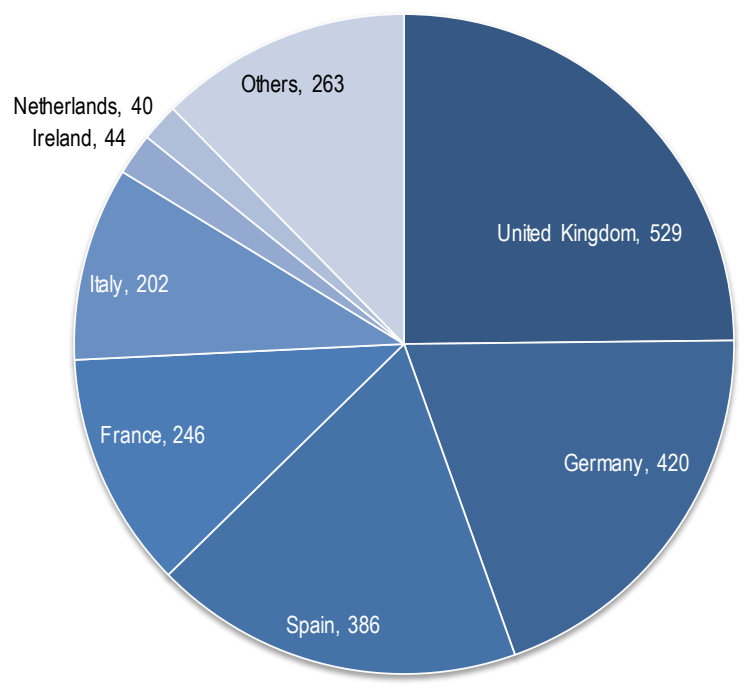

Note: Observations from Malta or Croatia are not available.

Source: $\quad$ OECD Secretariat calculations based on the EU Labour Force Survey (Eurostat).

\section{The effect of long-term residence on mobility}

47. Mobility rates differ markedly between TCN who are eligible as long-term residents and TCN who are not. Less than $0.2 \%$ of long-term resident TCN are observed to be mobile between EU countries, compared to $1.5 \%$ of $\mathrm{TCN}$ who have been resident for less than five years (see Figure 4). Long-term resident TCN are even only half as mobile as EU citizens. Overall, $62000 \mathrm{TCN}$ with less than five years residence were observed to be mobile in 2012, against only 30000 long-term resident TCN. More than half (57\%) of the mobile long-term resident TCN had been born outside the EU. 
DELSA/ELSA/WD/SEM(2016)13

Figure 4. Mobility rates by duration of residence, 2012

in percent

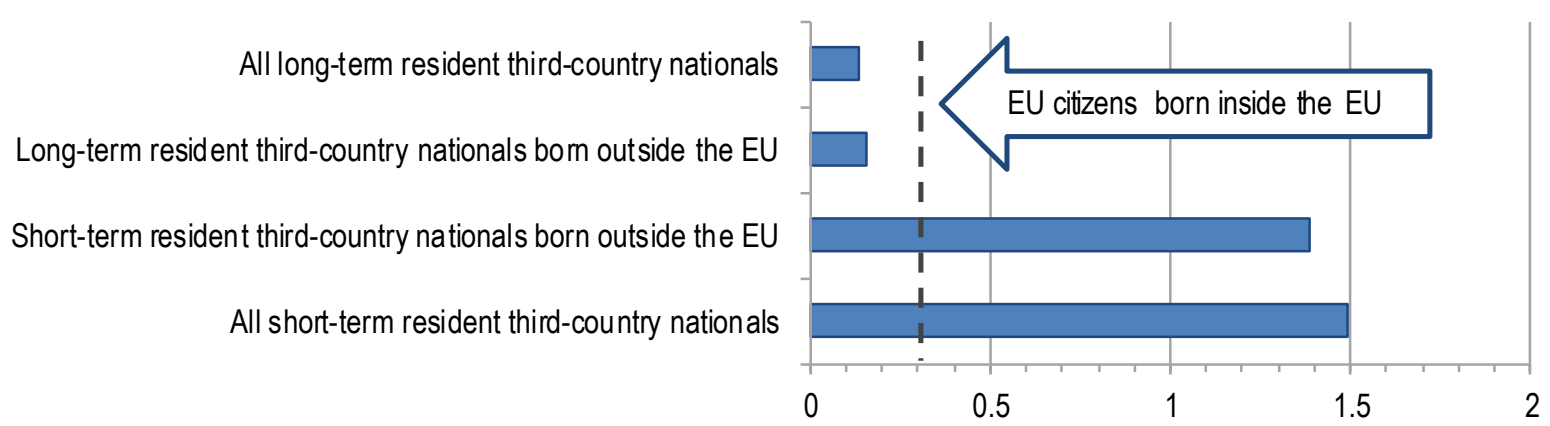

Note: $\quad$ Too few observations were available on TCN born inside the EU, whether short-term or long-term resident. Mobility involving Finland, Ireland, Malta or the Netherlands is only partially observed. TCN residing in Germany are only included if they were born there, as information on other places of birth is not available in this case.

Source: $\quad$ OECD Secretariat calculations based on the EU Labour Force Survey (Eurostat).

48. Several reasons likely contribute to the low mobility of long-term residents. Above all, the combination of long-term residence and mobility can only be observed when long-term residents are mobile but maintain their residence in the same EU country as before. If they instead move permanently, they are not counted as long-term residents at their new location, for several years. In addition, those who are inherently less mobile than the average among TCN are more likely to stay somewhere long enough to be eligible for long-term residence. Secondly, even those TCN who are relatively mobile but who would like to obtain long-term residence might permanently change their habits in response to the requirement of at least five years of continuous residence. Thirdly, older TCN likely meet this criterion in larger numbers, and it is often found that individuals become less mobile with age.

49. However, a simple comparison of average mobility rates (essentially a univariate analysis) says little about the effect that the status of long-term residence has on mobility. To better discern the effect, this paper employs a difference-in-difference (DID) approach. If one ignores issues of exogeneity for a moment, becoming eligible for long-term residence can be thought of as a treatment. It is administered to TCN, who are therefore the treatment group. The control group is made up of all those individuals who are foreigners in the country they are surveyed in, but who are also EU citizens. They are a suitable control group because they are likewise foreigners who in many cases migrated to their current country of residence, but their legal situation is unaffected by residence duration.

50. In this set-up, the hypothesis is examined that the treatment affects mobility (the outcome variable). To this end, the DID approach thus performs a double comparison. It firstly compares the mobility of TCN to the mobility of EU citizens residing outside their home country; this comparison is captured by a difference in mobility between these two groups. Secondly, this difference is calculated separately for TCN who are and who are not eligible for long-term residence. If a significant difference between the differences is found, one can conclude that the mobility of TCN changes as they become eligible for long-term residence, beyond the change one would have expected based on changes in the control group over the same period.

51. The caveat arises that the treatment is not fully exogenous because TCN can influence whether they receive the treatment or not. If they choose to stay in the same EU country for at least five years, they will normally receive the treatment; if they choose to leave before that, they will normally not. In such 
circumstances, an effect ascribed to the treatment could in fact arise from unobserved characteristics that are particularly common among those who choose to receive the treatment.

52. However, there are reasons to believe that this problem will remain limited here. Receiving a long-term residence status is beneficial, so that TCN do not have a reason to avoid treatment. Therefore, one does not need to worry that many TCN seek to avoid the treatment by changing their residence. In other words, exits from the treatment group should be uncorrelated with the effect of the treatment itself. Entries into the treatment group, on the other hand, can only occur five years prior to the treatment, but not in the year immediately preceding it. By consequence, the phenomenon of selection into the treatment group should affect TCN with various durations of residence, and not only those who receive the treatment. Yet factors that are roughly the same over time should cancel out in the DID approach, thus leaving the estimation of the treatment effect unaffected.

53. The core of the empirical model is a linear probability model. Across individuals indexed by $i$, the model relates a number of explanatory variables to an indicator variable $M_{i}$ that equals one if individual $i$ is observed to be mobile, and equals zero otherwise:

$$
M_{i}=\beta_{0}+\beta_{1} T C N_{i}+\beta_{2} L T R_{i}+\beta_{3}\left[T C N_{i} * L T R_{i}\right]+X_{i}^{\prime} \beta_{4}+\gamma_{i}+\delta_{t}+\varepsilon_{i}
$$

54. The key explanatory variables for the DID approach are $\operatorname{TCN}_{i}$ (indicating whether or not individual $i$ is a TCN), $L T R_{i}$ (indicating whether individual $i$ is eligible for long-term residence) and the interaction between these two variables. Their coefficients $\beta_{1}, \beta_{2}$ and $\beta_{3}$ are to be estimated. Since TCN make up the treatment group, $\beta_{1} T C N_{i}$ captures the difference between treatment and control group; $\beta_{2} L T R_{i}$ likewise captures the difference between short-term and long-term residents. If TCN eligible for long-term residence exhibit a particular mobility not captured by either, the estimate for $\beta_{3}$ will be significantly different from zero. Therefore, $\beta_{3}$ is the parameter of interest in this model. The remaining elements account for a constant part of $M_{i}\left(\beta_{0}\right)$ as well as for influences from certain observed characteristics of individual $i\left(X_{i}^{\prime} \beta_{4}\right)$, from a country fixed effect $\left(\gamma_{i}\right)$ and a year fixed effect $\left(\delta_{t}\right)$. Finally, $\varepsilon_{i}$ allows for random disturbances in the empirical relation.

55. The available micro data from the EU Labour Force Survey allow to account for a number of individual characteristics that might well affect mobility, such as sex, age group, education level, employment status, marital status, years since migration, the presence of a partner or children in the household and the country of birth (only at the level of regional groups). In addition, the age group at migration and presence of a child likely born in the country of residence can be constructed. Some other variables that might well affect mobility, such as home ownership, language abilities, or income (see the discussion in Chiswick and Miller, 2008) are not available from this data set.

56. The model is estimated using the treatment and control groups only. In each estimation, the sample is further restricted to observations from two consecutive years. While data from two consecutive points in time are necessary for a DID approach, data from earlier or later years might reflect events or trends only present in these years, which would dilute the estimation results. Over the year pairs 2011/2012, 2010/2011 and 2009/2010, the size of the treatment group varies little in the range between 15 and 16 million individuals, based on $105000-117000$ observations. The control group grows over the years from 8.9 million to 10.4 million and is based on $77000-90000$ observations.

57. Estimation results for $\beta_{3}$, the parameter of interest, are reported in Table 4 where bold figures indicate the estimated coefficient, followed by the standard error of the estimate. For three pairs of years, the results of three slightly different model specifications are reported. All specifications include the key variables needed for the DID approach as well as a year fixed effect for the second respective year and a constant. That apart, the first specification only includes a set of individual covariates, consisting of the 
observed characteristics mentioned above and indicators for country of birth. The second specification adds fixed effects for the country the individual is surveyed in and for another EU country where the individual resided last year (if applicable). Finally, the third specification features only the observed individual characteristics but accounts for the possibility that standard errors in the treatment and control groups are clustered. In this case, unadjusted standard errors would be too low and would thereby exaggerate the precision of the estimate. ${ }^{4}$

Table 4. Estimated effects of long-term residence on mobility of TCN, 2009-2012

\begin{tabular}{l|c|c|c}
\hline Model version & $2009 / 10$ & $2010 / 11$ & $2011 / 12$ \\
\hline Individual covariates & 0.031 & 0.037 & 0.055 \\
& 0.001 & 0.001 & 0.001 \\
Individual covariates and country fixed effects & $\mathbf{0 . 0 2 3}$ & $\mathbf{0 . 0 2 2}$ & $\mathbf{0 . 0 2 9}$ \\
& 0.001 & 0.001 & 0.001 \\
Individual covariates and clustered standard errors & $\mathbf{0 . 0 3 1}$ & $\mathbf{0 . 0 3 7}$ & $\mathbf{0 . 0 5 5}$ \\
& 0.003 & 0.000 & 0.000 \\
\hline
\end{tabular}

Note: $\quad$ Bold figures indicate estimated coefficients, the remaining figures their standard errors. All estimates are statistically significant at the $2 \%$ level. Mobility involving Finland, Ireland, Malta or the Netherlands is only partially observed. TCN residing in Germany are only included if they were born there, as information on other places of birth is not available in this case.

Source: $\quad$ OECD Secretariat calculations based on the 2008 ad-hoc module of the EU Labour Force Survey (Eurostat).

58. All estimates in Table 4 are statistically significant at the $1 \%$ significance level - with the exception of the estimate for the third specification in 2009/2010, which is nevertheless still significant at the $2 \%$ significance level. In the context of a linear probability model, the estimates can be interpreted as marginal probabilities: other things equal, they suggest that TCN eligible for long-term residence are between $2.2 \%$ and $5.5 \%$ more likely to be mobile within the EU than TCN who are not eligible for longterm residence. The magnitude of the effect appears to increase over the years considered here, from $2.3 \%$ to $2.9 \%$ or from $3.1 \%$ to $5.5 \%$, depending on the model specification. Given that 30000 long-term resident TCN were observed to be mobile in 2012 (see above), an effect of 5\% would imply that about 1400 longterm resident TCN were mobile due to their long-term residence status.

59. Tables B.1 through B.3 in the Annex provide details of the estimation results. While the variables considered collectively explain some of the variation in observed mobility, their joint explanatory power is very low, judging from the R-squared value, for example. Yet low values of R-squared commonly arise with estimation approaches that are largely based on fixed effects, and the DID approach taken above falls into this category. The important elements of the DID model seem to capture empirical patterns: also the estimates for $\beta_{1}$ and $\beta_{2}$ are throughout significant at the $5 \%$ significance level. These estimates suggest that TCN are significantly less likely to be mobile than foreign EU citizens, in line with arguments that mobility of the former are much more constrained. In line with Figure 4, individuals who have stayed in the same EU country for five years or more (so that $L T R_{i}=1$ ) are also significantly less likely to be mobile than those who have stayed for a shorter time.

60. The results for the other explanatory variables offer some more notable insights. First, while age appears to matter for the explanation of mobility in one model specification, the size of its effect approaches zero. By contrast, the estimated country fixed effects suggest that having resided in certain countries one year earlier can explain mobility almost entirely. Women appear to be slightly less mobile

$4 \quad$ A fourth specification would ideally combine clustered standard errors with individual covariates and country fixed effects. However, attempts to fit it render almost all estimates statistically insignificant. 
than men, but individuals with a tertiary education are more mobile than those with a medium or low level of education. While the presence of a child reduces mobility, it does not appear relevant in this context where the child was born. Married individuals in turn exhibit slightly higher mobility. Finally, years since migration was not included as an explanatory variable because it is a linear combination of age and age at migration, so that its inclusion would create perfect multicollinearity.

61. One could imagine many more variables that affect mobility but could not be included in the models above. For example, in the case of a TCN who has found many friends, or has bought a house, or sees particularly promising career opportunities in the area, the probability of a move should decrease. As all these examples would also make a TCN more likely to become a long-term resident, the absence of these variables could in principle pose a problem for the identification of any effect from long-term residence: long-term residence could capture the joint effect of these unobservable variables precisely because long-term residents might be selected according to these variables. Yet the differencing involved in the DID approach ensures that unobserved variables cancel out as long as they are similar either between treatment and control group or over years of residence.

62. The fact that different model specifications applied to different pairs of years produced similar results for the key variables points to an empirical regularity rather than a spurious finding. To further assess the robustness of the results, Figure 5 depicts the trends in (unconditional) mobility rates of the treatment and control groups for the years 2011/2012. Trends are shown only from the third year of residence onwards because mobility rates are much higher, and probably less reliably estimated, during the first two years of residence.

Figure 5. Mobility rates of treatment and control groups, 2011/2012

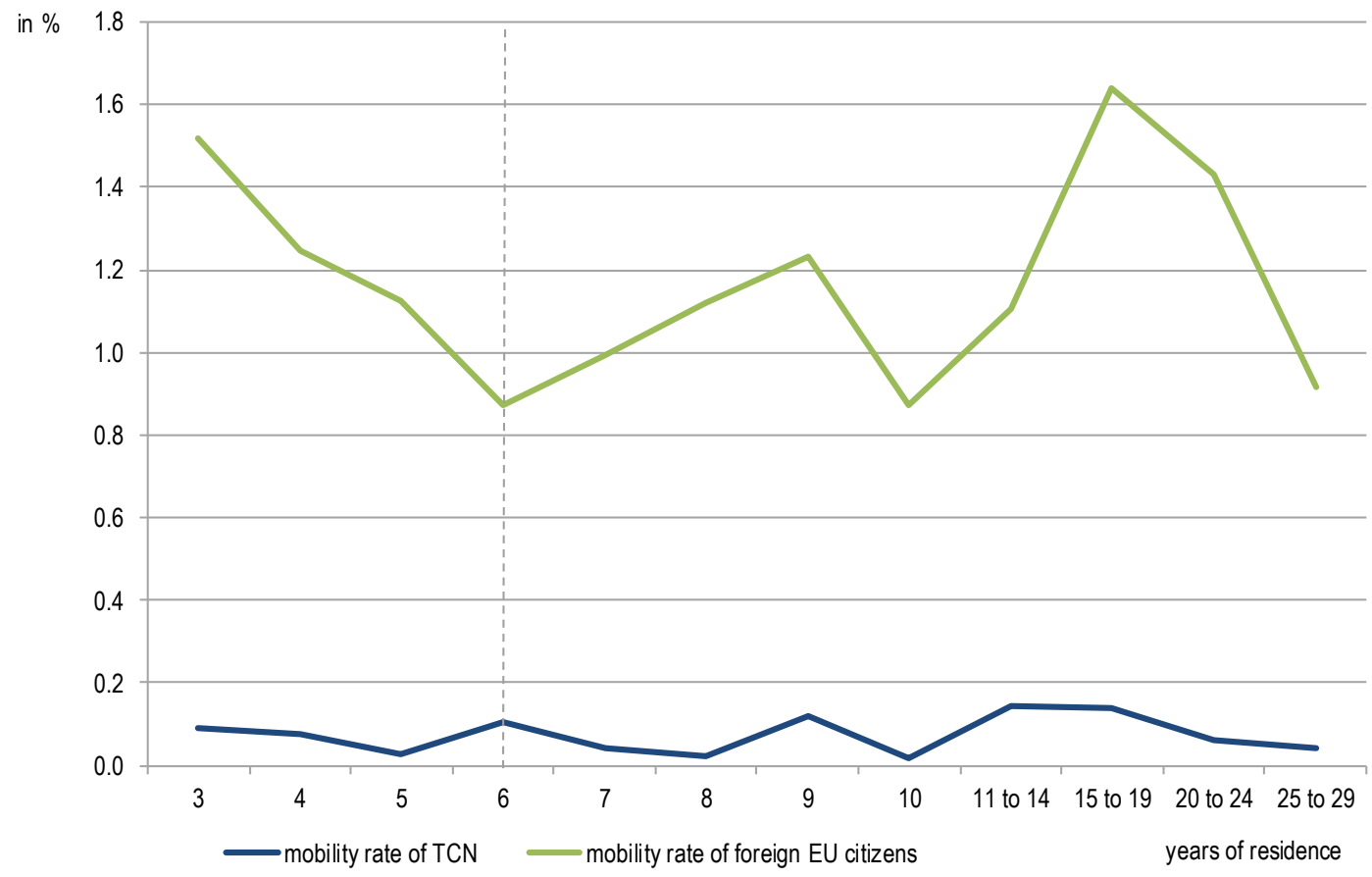

Note: $\quad$ Mobility involving Finland, Ireland, Malta or the Netherlands is only partially observed.

Source: $\quad$ OECD Secretariat calculations based on the EU Labour Force Survey (Eurostat).

63. A crucial assumption involved in the DID approach is that the treatment and control groups exhibit similar trends before the treatment takes effect. While the variation in the mobility rate of foreign 
EU citizens is much stronger in Figure 5, it by and large falls and rises in line with the mobility rate of TCN (above 10 years of residence, rates might be less comparable due to the switch in the data to year brackets). A notable exception from the correlation of the two mobility rates in Figure 5 occurs at five to six years of residence - precisely when TCN normally become eligible for long-term residence status. At this point, the mobility rate of TCN rises substantially while the mobility rate of foreign EU citizens continues to fall. Figure 5 thereby appears to confirm the econometric results.

64. Finally, one could ask how the econometric results depend on the way mobility is measured in this paper. To recall, mobile individuals either resided in another EU country one year before or currently work in another EU country. For the analysis above, it would not suffice to only count those working abroad as mobile, not least because the number of mobile TCN in the sample would drop. As observations on the country of residence last year are thus essential here, so is the definition of years of residence: stays abroad up to one year are not counted as interruptions of the habitual residence, so that mobility can be observed together with long-term residence in the same EU country.

65. To gauge the effect of greater mobility among TCN on European labour markets, it is worth noting that the labour market situation of mobile TCN who are eligible for long-term residence differs markedly from that of other TCN (see Figure 6): the former are employed in almost all cases and are virtually never unemployed. By contrast, both the long-term resident and all TCN together exhibit employment rates approaching 50\% and unemployment rates around $13 \%$. The effect identified above on the mobility of long-term resident TCN thus translates directly into an effect on EU labour markets.

Figure 6. Labour market status of TCN, 2012

shares in percent

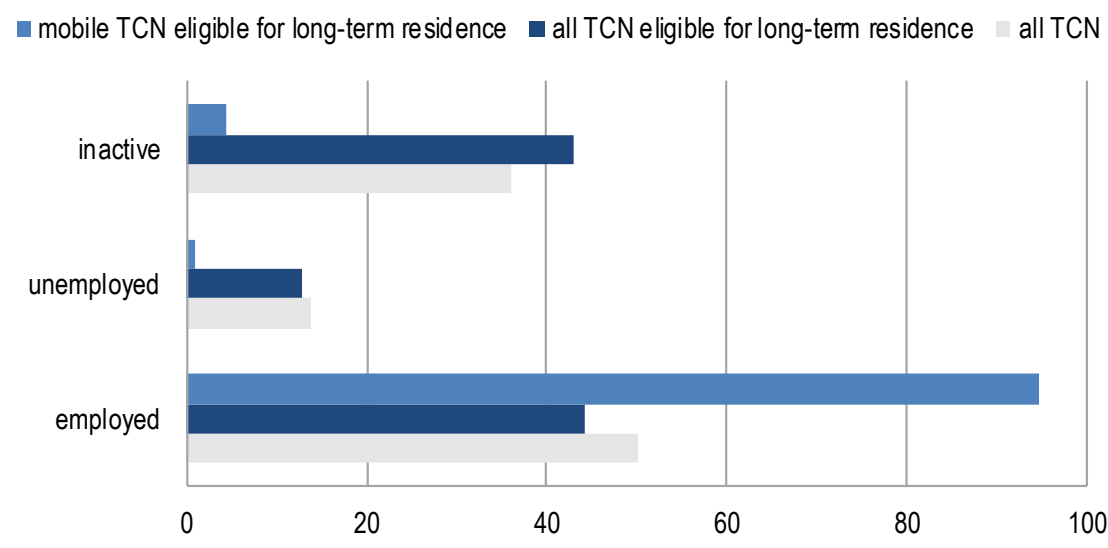

Note: $\quad$ Mobility involving Finland, Ireland, Malta or the Netherlands is only partially observed.

Source: OECD Secretariat calculations based on the EU Labour Force Survey (Eurostat).

66. In conclusion, the DID approach in this section has produced evidence that becoming eligible for a long-term residence permit is associated with a small yet significant increase in the mobility of TCN. By including covariates, the effect has been isolated from the effects of observed characteristics; by construction, the DID approach has led the effects of slowly moving unobserved variables to cancel out. Quickly changing unobserved variables might well be rare in this context, with the treatment only occurring after five years. While these results also seem robust to several modifications, the next section will reinforce them through another empirical test of the hypothesis that TCN are more mobile if they enjoy the rights to greater freedom of movement within the EU. 


\section{TCN who have naturalised}

67. If there is an effect of long-term residence on mobility, a similar if not stronger effect on mobility may be expected from acquiring EU citizenship: through naturalisation, TCN obtain the full freedom of movement within the EU, while the rights accorded to long-term residents might in many cases fall short of the full freedom of movement. After some overview of naturalised EU citizens, this section will seek to identify the effect of naturalisation on mobility, essentially using the same econometric techniques as above.

68. More than 10 million EU citizens were recorded as naturalised citizens in the AHM 2008. For more than 3 million of them, residing in Germany, information on the country of birth was not collected. About 4.8 million naturalised EU citizens can be identified as born in non-EU countries, while 2.3 million were born in EU countries. By comparison, 14.2 million TCN were residing in EU countries (EU27) at the time, of whom 11.9 million were born outside the EU, and 2.3 million inside. Hence, individuals born in EU countries were much more frequent among the naturalised than among TCN. Those born in the EU accounted for $33 \%$ of all naturalised EU citizens, followed by $22 \%$ born in African countries, $16 \%$ born in Asian countries without the Near and Middle East, $13 \%$ born in European countries that are not members of the EU or the EFTA, and $11 \%$ born in South and Central American countries. Some 3\% were born in the Near and Middle East, and only about 1\% each in North America, EFTA countries and Australia and Oceania.

69. In fact, many among the naturalised who were born in EU countries might have been EU citizens at birth and then eventually acquired the citizenship of another EU country. To approximate the group of naturalised EU citizens who were born as TCN, this section will therefore draw repeatedly on those born outside the EU when using data from the AHM 2008. Figure 7 shows the EU countries in which the individuals belonging to this group reside.

\section{Figure 7. Naturalised EU citizens born outside the EU, 2008}

in thousands

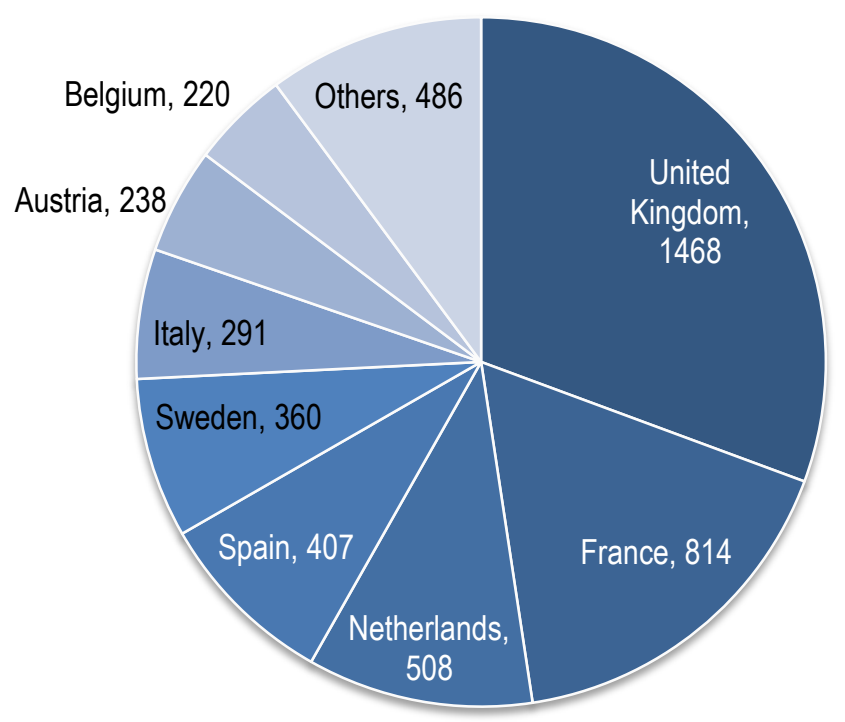

Note: $\quad$ No data was available for Finland, Malta and Croatia. Germany is not included because, in this case, those born outside the EU cannot be distinguished from those born in EU countries.

Source: OECD Secretariat calculations based on the 2008 ad-hoc module of the EU Labour Force Survey (Eurostat). 
70. As is shown in Figure 8, some quantitatively important developments have affected the number of new naturalisations in the EU27 after 2008. For Indian nationals, the number of new naturalisations had fluctuated around 16000 each year between 2004 to 2008, then jumped up between 2008 and 2009 and stabilised at levels above 30000 a year. Naturalisations of nationals of the Russian Federation, Nigeria, China and Brazil have also increased strongly in the years from 2007, but stayed much behind the levels for Indian nationals. Finally, citizens of the United States are apparently naturalised in comparatively low numbers of around 5000 each year, without a trend in recent years.

Figure 8. Naturalisations by previous nationality, selected countries, 2000-2012

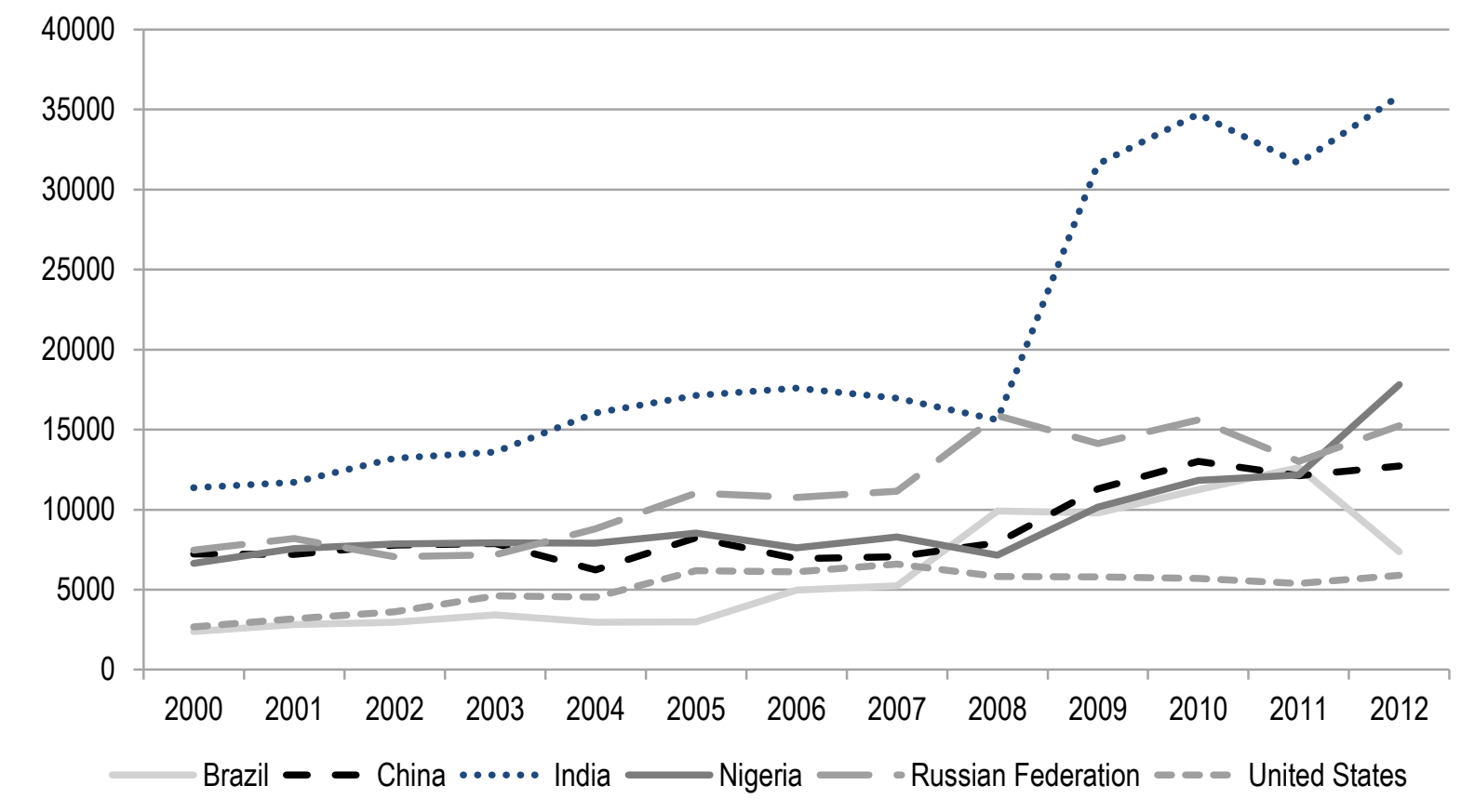

Note: $\quad$ The drop in 2012 of the series for Brazil might be due to 2012 data not yet being available for all EU countries.

Source: International Migration Database.

71. By contrast, naturalisations of Turkish nationals (not shown in Figure 8) have fallen strongly over time, from 133000 in 2000 to about 50000 in recent years. Algerian nationals also account for high numbers of naturalisations, at a largely stable level of around 20000 throughout the period. ${ }^{5}$ Overall, the IMD database suggests that there has been a rise in naturalisations of TCN in the EU, from 552000 in 2000 to almost 680000 by 2010 and 634000 in 2012.

\section{The effect of naturalisation on the mobility of TCN}

72. Among all naturalised EU citizens, more than 21000 were observed to be mobile in 2008, based on data from the AHM. Although those born outside the EU represent a much larger group among the naturalised than those born inside the EU, those born outside the EU account for less than $40 \%$ of the mobile individuals among the naturalised. The mobility rate of those born in non-EU countries accordingly approaches zero, but stands close to $0.6 \%$ for those born in EU-countries (see Figure 9). In the same data set, 15000 TCN were observed to be mobile in 2008 , $87 \%$ of whom were born outside the EU. There were

5 In the IMD database, naturalisations of Algerian nationals are only a fraction of this level 2004, 2006 and 2007, very likely as a result of data from France being missing for these years. 
roughly twice as many TCN as naturalised EU citizens in 2008; by consequence, the naturalised exhibited on average a substantially higher mobility rate $(0.3 \%)$ than $\mathrm{TCN}(0.1 \%)$, and about the same mobility rate as native-born EU citizens.

Figure 9. Mobility rates by citizenship, 2008

in percent

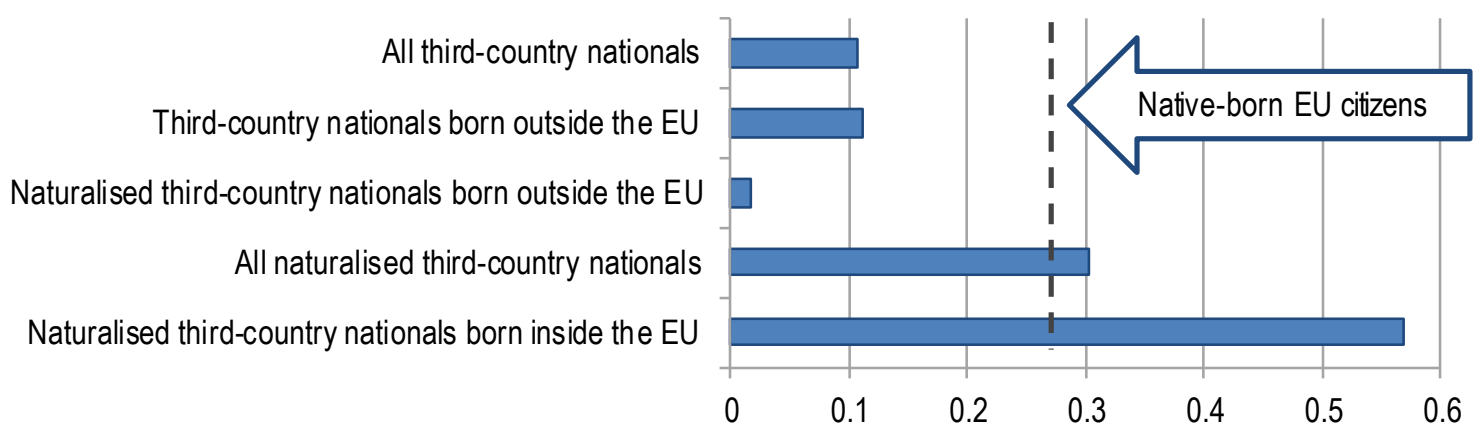

Note: $\quad$ Too few observations were available for TCN born inside the EU. No data was available for Finland, Malta and Croatia Mobility involving Ireland or the Netherlands is only partially observed. TCN residing in Germany are only included if they were born there, as information on other places of birth is not available in this case.

Source: OECD Secretariat calculations based on the 2008 ad-hoc module of the EU Labour Force Survey (Eurostat).

73. To estimate the effect of naturalisation on mobility, one might want to take much the same approach as in the previous section. However, naturalisation would then have to be regarded as a treatment, although it is in all likelihood not exogenous at all: individuals who naturalise normally have to initiate this process and carry through with at times lengthy procedures. It appears very likely that individuals with certain unobserved characteristics will thus be over-represented among those who naturalise. For example, they might be more entrepreneurial or more open to changes, which would also make them more mobile. When mobility is the outcome variable, the coefficient for naturalisation might therefore capture unobserved characteristics of those who naturalise.

74. A number of research papers confirm that those who naturalise are a particular selection, differing in observable and unobservable characteristics from those who do not naturalise (see e.g. Scott, 2008, Engdahl, 2011, and Steinhardt, 2012). Patterns across countries are documented in OECD (2010), showing for example that migrants are more likely to naturalise if they come from low-income countries, and especially from African countries. This paper thus takes an altogether different approach to estimating the effect of naturalisation on mobility, in order to rule out that the effect identified arises partly or entirely from unobserved differences between groups.

75. The approach in this section begins with the observation that citizens of countries that accede to the EU are TCN until the accession but then suddenly turn into EU citizens. This way of becoming an EU citizen differs from naturalisation notably because all citizens of the acceding country automatically become EU citizens at the same time. By contrast, only those TCN are naturalised who apply for it and who successfully complete the process. Naturalisation might therefore concern only a particular selection of individuals, while accession to the EU affects all citizens of the acceding country. To estimate the effect of obtaining EU citizenship on mobility without possible bias from the selection involved in naturalisation, this section thus focuses on the mobility of citizens of the ten new member states (NMS10) during the accession period. 
76. Concretely, only citizens of NMS10 countries are considered who already live outside the country whose citizenship they hold, but in another EU country (including other NMS10 countries after their accession in May 2004). Until the date of accession, they are TCN who reside in EU countries, comparable to TCN from European countries outside the EU and the EFTA. Before accession, some of them might have already enjoyed a greater freedom of movement than other TCN, but likely still faced restrictions in many EU countries. Notably, EU15 countries did not grant free access to their labour markets, and even after accession, most EU15 countries only granted access after a transition period. Perhaps the most significant restriction on the mobility of NMS10 citizens was thus lifted in different countries at different times.

77. In 2011, Austria, Belgium, Denmark and Germany were the last EU15 countries to give labour market access to all NMS10 citizens. Since the accession in 2004, NMS10 citizens had already taken up many new opportunities for mobility within the EU, and any temporary initial effects might have petered out. In this context, the openings of the last four labour markets in mid-2011 were nevertheless associated with a secular increase in the mobility of NMS10 citizens, as Figure 10 shows: after the number of mobile NMS10 citizens observed in Austria, Belgium, Denmark or Germany had fluctuated between 32000 and 56000 in the years 2009-2011, it jumped up to 77000 in 2012, the first year after the opening of the labour market. The vast majority of mobile NMS10 citizens had been residing in another EU country (while not the country whose citizenship they hold) and had moved to the countries opening their labour markets. The remaining mobile NMS10 citizens were residing in these four countries but worked in another EU country.

Figure 10. Mobility of NMS10 citizens in Austria, Belgium, Denmark and Germany, 2009-2012

A. Levels of mobility

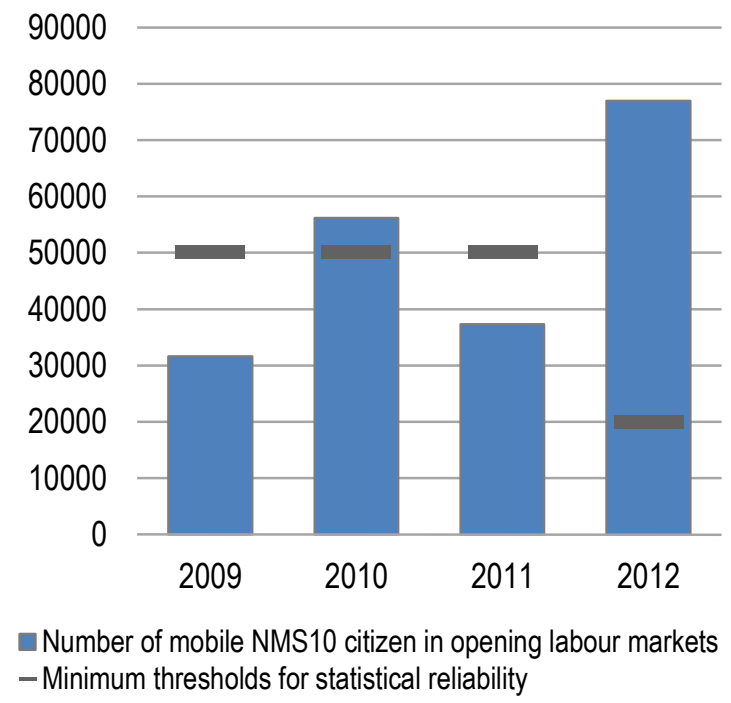

B. Share in total mobility of NMS10 citizens

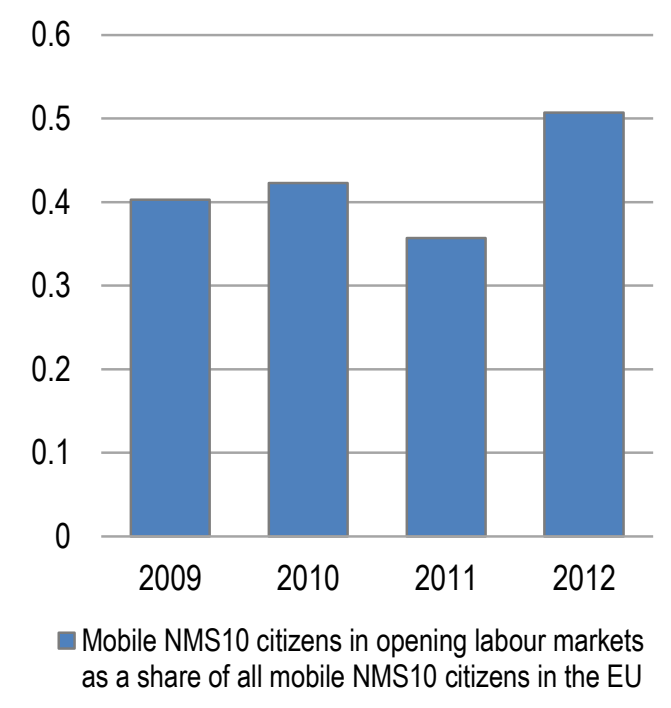

Note: $\quad$ Due to limited sample sizes, estimated figures below the EU-wide thresholds (as indicated) might be unreliable.

Source: $\quad$ OECD Secretariat calculations based on the EU Labour Force Survey (Eurostat).

78. Over the period 2009-2012, the total number of NMS10 citizens residing in the EU but outside the country whose citizenship they hold increased from just over 2 million in 2009 to 2.7 million in 2012, according to the EU Labour Force Survey. The total number of mobile individuals observed among them also rose, from 78000 in 2009 to 152000 in 2012. Yet this overall increase does not explain the increase observed in Austria, Belgium, Denmark and Germany after 2011: as shown in the second panel of Figure 
10, the number of mobile NMS10 citizens observed in these four countries also jumps up when expressed as a share of all mobile NMS10 citizens in the EU.

79. Hence the mobility of NMS10 citizens observed in Austria, Belgium, Denmark and Germany suddenly increased after the labour market opening, both in absolute and relative terms. Unlike in cases of individual naturalisation, this effect on mobility cannot be attributed to the characteristics of a particular selection, since all NMS10 citizens are affected by the opening of labour markets to them. Rather, these findings indicate that the freedom of movement associated with EU citizenship by and of itself has a positive effect on mobility.

80. The following model is used to investigate the effect econometrically. As before, the model combines a DID approach with a linear probability model:

$$
m_{i}=\beta_{0}+\beta_{1} N M S 10_{i}+\beta_{2} 2012_{t}+\beta_{3}\left[N M S 10_{i} * 2012_{t}\right]+X_{i}^{\prime} \beta_{4}+\gamma_{i}+\varepsilon_{i}
$$

81. In this set-up, the labour market opening in 2011 constitutes the treatment and NMS10 citizens who already reside in another EU country thus make up the treatment group. The indicator of mobility $m_{i}$ equals one if an individual's mobility involves one of the four countries opening their labour markets in 2011. The key explanatory variables are whether or not an individual is an NMS10 citizen $\left(N M S 10_{i}\right)$, whether an observation falls into the year after the labour market opening $\left(2012_{t}\right)$ and the interaction of these two indicators $\left(N M S 10_{i} * 2012_{t}\right)$. A country fixed effect is denoted $\gamma_{i}$ as before; due to the inclusion of $2012_{t}$, this specification does not need a year fixed effect. The parameter of interest is again $\beta_{3}$ : the estimate of this coefficient indicates whether the mobility of NMS10 citizens in 2012 differs significantly from the mobility one would have expected, given concurrent developments in the control group.

82. The analysis below considers two alternative control groups, neither of which appears perfectly suited. TCN who are nationals of European countries outside EU and EFTA serve as the first control group. With many among the NMS10 citizens, they share the region of origin, but their mobility is much more constrained than that of NMS10 citizens - after all, NMS10 citizens could be mobile within the EU well before the last four countries opened their labour markets to them. Therefore, nationals of Romania and Bulgaria (henceforth abbreviated as NMS2 citizens) are considered as another control group. ${ }^{6}$ Their countries acceded to the EU in 2007 , so that they were probably also facing lower constraints to their mobility than TCN. At the same time, the four labour markets concerned were not opened to them in 2011 or 2012, so that their legal situation was less favourable than the situation of NMS10 citizens.

83. Both control groups are compared to the treatment group in Figure 11. The (unconditional) mobility rate of TCN from European countries outside EU and EFTA, depicted in Panel A, remains at a very low level throughout the period 2007-2012, while the mobility rate of the treatment groups varies comparatively strongly. Still, the two rates develop roughly in parallel up to 2010, and diverge significantly thereafter: while the mobility rate of the control group then rises very slightly and stays stable subsequently, the mobility rate of the treatment group increases strongly over this time, especially in 2011. The mobility rate of the alternative control group, made up of nationals of Bulgaria and Romania (and possibly Croatia), reaches the same levels as that of NMS10 during the years 2007-2010 (see Panel B of Figure 11). This confirms the expectation that the two groups might exhibit very similar mobility behaviour. The year 2008, however, constitutes an exception: the mobility rate of the control group suddenly rises, only to fall back to the previous level in the following year. This spike very likely reflects a round of initial effects that followed the accession of Bulgaria and Romania to the EU in 2007. After 2010,

6 To avoid problems of small sample sizes, nationalities recorded as "NMS3", i.e. Romania, Bulgaria and Croatia, are also counted towards the control group. Croatian nationals likely make up a small share. 


\section{DELSA/ELSA/WD/SEM(2016)13}

however, the mobility rates of treatment and control group strongly diverge also in this case. In both cases, the assumption of common trends prior to 2011 seems to hold.

Figure 11. Mobility rates of treatment and control groups, 2007-2012

in percent

A.TCN from Europe without EU/EFTA as control group

B.NMS2 and NMS3 citizens as control group
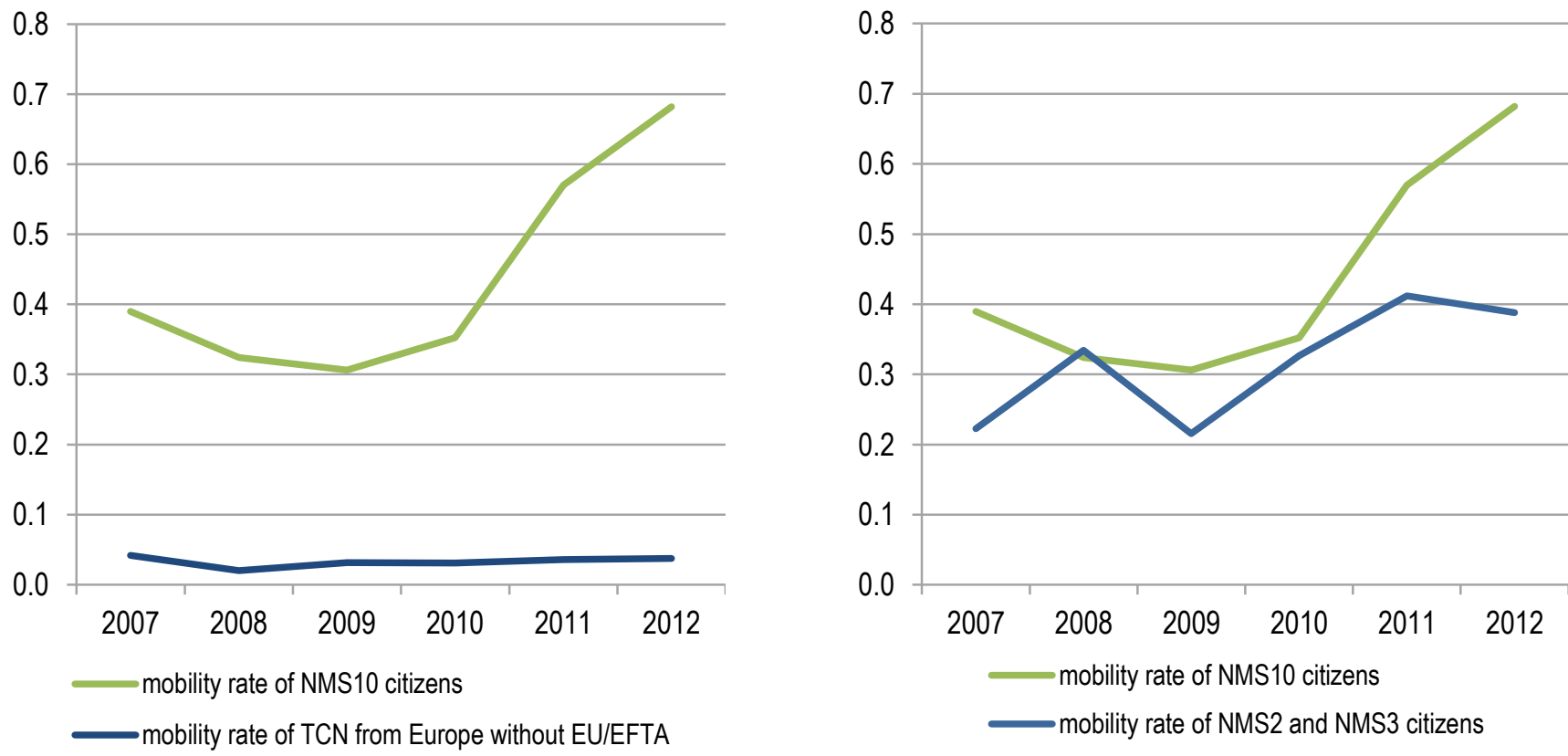

Note: $\quad$ Mobility involving Finland, Ireland, Malta or the Netherlands is only partially observed. TCN residing in Germany are not included, as information on their place of birth is not available in this case.

Source: OECD Secretariat calculations based on the EU Labour Force Survey (Eurostat).

84. The treatment group comprises of over 2 million individuals in both 2011 and 2012, based on between 18000 and 20000 observations. Estimation begins with TCN from European countries outside EU and EFTA as control group; its size has grown from 4.3 million in 2011 to 4.5 million in 2012, based on $48000-49000$ observations. Two slightly different model specifications are estimated, one with individual covariates only and one with additional country fixed effects. They use the same individual covariates as in the previous analysis. Detailed results are reported in Tables B.4 and B.5 in the Annex, respectively.

85. In both estimations, the estimates for the parameter of interest, $\beta_{3}$, are statistically significant at the $0.1 \%$ significance level. The point estimate rises from 0.003 to 0.006 as the additional country fixed effects are included. It suggests that NMS10 citizens in 2012 were slightly more likely (by between $0.3 \%$ and $0.6 \%$ ) to be mobile in conjunction with the opening labour markets than suggested by previous comparisons between them and the control group. In other words, there is evidence that the right to labour market access had a small but significant effect on the mobility of NMS10.

86. This impression is confirmed when the two model specifications are estimated anew, this time using NMS2 citizens as control group. The size of this control group stood at 2.7 million in both years, based on around 20000 observations. Results from this estimation can be found in Tables B.6 and B.7 in the Annex. For $\beta_{3}$, again a value of 0.003 is estimated without country fixed effects. This estimate was 
only just significant at the 5\% significant level. However, when country fixed effects are introduced, the point estimate remains essentially the same but turns out to be again statistically significant at the $1 \%$ significance level.

87. In fact, obtaining the same estimation results with two different but plausible control groups is one way to show the robustness of the results. In the estimations with individual covariates only, one can also account for clustered standard errors in the treatment and control groups. While standard errors tend to increase as a result, the estimates of $\beta_{3}$ remain statistically significant at least at the $5 \%$ significance level. As before, using clustered standard errors renders almost all results insignificant if the country fixed effects are also included. Finally, when the notion of mobility here is limited to those who work abroad, the results remain significant.

88. These econometric analyses have thus confirmed the graphical impression that the mobility of NMS10 citizens grew particularly quickly when they could access the labour markets of Austria, Belgium, Denmark and Germany. Quantitatively, a small effect on mobility has been found, which is not surprising when thought of as a marginal effect: before 2011, NMS10 citizens could already move freely throughout the EU and could access most EU labour markets, so that the opening of the last four labour markets in 2011 did not change their situation much. While the effect from this enlargement of rights cannot simply be equated with the effect of naturalisation on the mobility of TCN, it might well approach it for those TCN who become long-term residents before they naturalise. In these cases, the effect of naturalisation should reflect the marginal enlargement of rights. In any case, the findings suggest that full labour market access, as is typically only available to citizens, matters for mobility. 


\section{CONCLUSIONS}

89. This paper has sought to explore how long-term residence and naturalisation affect the intra-EU mobility of third-country nationals. As both long-term residence and naturalisation confer greater opportunities for mobility within the EU, one would expect positive effects. However, long-term resident third-country nationals a priori appear less mobile than others, as do naturalised EU citizens who were born outside the EU. To isolate causal effects on mobility in each case, one has to control for a range of other variables affecting mobility, and one needs to account for the possibility that long-term residents and those who naturalise represent a particular selection, featuring particular unobserved characteristics.

90. The difference-in-difference approach taken in this paper identifies positive causal effects of long-term residence and naturalisation on the mobility of third-country nationals in the EU. The effect of long-term residence is sizeable - the results suggest that third-country nationals with long-term residence are 5\% more likely to be mobile than they would have been without this status. The effect of naturalisation is estimated from a natural experiment in 2011 when labour markets in four EU countries were opened to citizens of EU accession countries. Because these citizens all obtained labour market access at the same time, results should not suffer from selection bias. The small positive effect found in this context suggests once again that intra-EU mobility increases when constraints on mobility are lifted.

91. In turn, these results imply that the mobility of third-country nationals is constrained, considerably so for third-country nationals who are not long-term residents and still somewhat for those who are. If the legal and practical constraints are reduced, the mobility of third-country nationals will in all likelihood increase. As a result, mobile third-country nationals could contribute more to rapid labour market adjustment in the EU. The greater number and variety of opportunities that third-country nationals could then take up in other EU countries would also make EU countries a more attractive destination for skilled migrants from outside the EU. 


\section{REFERENCES}

Amuedo-Dorantes, C. and De la Rica, S. (2010), "Immigrants' Responsiveness to Labor Market Conditions and Their Impact on Regional Employment Disparities: Evidence from Spain " SERIEs 1, p. $387-407$

Arslan, C., J.-C. Dumont, Z. Kone, Y. Moullan, C. Ozden, C. Parsons and T. Xenogiani (2014), “A New Profile of Migrants in the Aftermath of the Recent Economic Crisis", OECD Social, Employment and Migration Working Papers, No 160, OECD Publishing, Paris, http://dx.doi.org/10.1787/5jxt2t3nnjr5-en.

Åslund, O. (2005), "Now and Forever? Initial and Subsequent Location Choices of Immigrants." Regional Science and Urban Economics 35, p. 141-165

Beine, M., Bourgeon, P. and Bricongne, J.-C. (2013), "Aggregate Fluctuations and International Migration"

Borjas, G. J. (2001), "Does Immigration Grease the Wheels of the Labor Market?" Brookings Papers on Economic Activity 2001, p. 69-133

Bratsberg, B., J.F. Ragan Jr, and Z. M. Nasir (2002), "The Effect of Naturalization on Wage Growth: A Panel Study of Young Male Immigrants." Journal of Labor Economics 20, p. 568-597

Cadena, B. C. and B. K. Kovak (2013), "Immigrants Equilibrate Local Labor Markets: Evidence from the Great Recession", NBER Working Paper 19272

Chiswick, B. R. and P.W. Miller (2008), "Citizenship in the United States: The Roles of Immigrant Characteristics and Country of Origin", IZA Discussion paper No. 3596

Di Addario, S. (2011), "Job Search in Thick Markets", Journal of Urban Economics 69, p. 303-318

Edo, A. and J. Jarreau (2014), "Naturalization and the Labour Market Outcomes of Immigrants: Evidence from France"

EMN - European Migration Network (2013), "Intra-EU Mobility of Third-Country Nationals”

Engdahl, M. (2011), "The Impact of Naturalisation on Labour Market Outcomes in Sweden”, in Naturalisation: A Passport for the Better Integration of Immigrants?, p. 99.

Eurostat (2010), "Report on the Quality of the LFS Ad Hoc Module 2008 on the Labour Market Situation of Migrants and Their Descendants", Doc. Eurostat/F2/EMPL/22/10

Eurostat (2013), "EU Labour Force Survey. Explanatory Notes" 
Helsley, R. W. and W. C. Strange (1990), "Matching and Agglomeration Economies in a System of Cities", Regional Science and urban economics 20, p. 189-212

Jauer, J., T. Liebig, J. P. Martin and P. A. Puhani (2014), "Migration as an Adjustment Mechanism in the Crisis? A Comparison of Europe and the United States", OECD Social, Employment and Migration Working Papers No. 155, OECD Publishing, Paris, http://dx.doi.org/10.1787/5jzb8p51gvhl-en

Keeton, W. R. and G.B. Newton (2005), "Does Immigration Reduce Imbalances Among Labor Markets or Increase Them? Evidence from Recent Migration Flows" Federal Reserve Bank of Kansas Economic Review 2005, p. 47-79

Kok, S. (2014), "Matching Worker Skills to Job Tasks in the Netherlands: Sorting into Cities for Better Careers", IZA Journal of European Labor Studies 3, p. 1-36

OECD (2010), "Naturalisation and the Labour Market Integration of Immigrants", in International Migration Outlook 2010, OECD Publishing, Paris.

DOI: http://dx.doi.org/10.1787/migr_outlook-2010-7-en

OECD (2015), "Third-Country Nationals in the European Union", in OECD and EU , Indicators of Immigrant Integration 2015: Settling In, OECD Publishing, Paris.

DOI: http://dx.doi.org/10.1787/9789264234024-17-en

Petrongolo, B. and Pissarides, C.A. (2006), "Scale Effects in Markets with Search", Economic Journal 116, p. $21-44$

Puhani, P. A. (2001), "Labour Mobility: An Adjustment Mechanism in Euroland? Empirical Evidence for Western Germany, France and Italy", German Economic Review 2, p. 127-140

Røed, M. and P. Schøne (2012), "Does Immigration Increase Labour Market Flexibility?", Labour Economics 19, p. 527-540

Sarvimäki, M., R. Uusitalo and M. Jantti (2010), "Long-Term Effects of Forced Migration", IZA Discussion Paper 4003

Schündeln, M. (2014), "Are Immigrants More Mobile than Natives? Evidence from Germany", Journal of Regional Science 54,p. 70-95

Scott, K. (2008), "The Economics of Citizenship: Is There a Naturalization Effect?" in The Economic Consequences of Citizenship Ascension. A Cross Country Comparison

Steinhardt, M. F. (2012), "Does citizenship matter? The economic impact of naturalizations in Germany", Labour Economics 19, p. 813-823 


\title{
ANNEX A: KEY VARIABLES IN THE EU LABOUR FORCE SURVEY
}

\author{
Table A.1. Variables in the EU Labour Force Survey
}

Panel A.1 Variable: Nationality, 2009-2012

\begin{tabular}{l|r}
\hline Nationality & Observations (in \%) \\
\hline EFTA countries & 1.8 \\
Other Europe & 42.7 \\
Outside Europe & 53.8 \\
Missing values & 1.7 \\
\hline
\end{tabular}

Panel A. 3 Variable: Residence one year before, 2009-2012

\begin{tabular}{l|r}
\hline $\begin{array}{l}\text { Country of residence } \\
\text { one year before }\end{array}$ & Observations (in \%) \\
\hline Same country & 77.9 \\
Another country & 1.6 \\
Missing values & 20.5 \\
\hline
\end{tabular}

Panel A.2 Variable: Years of residence, 2009-2012

\begin{tabular}{l|r}
\hline Years of residence & Observations (in \%) \\
\hline Resident by birth & 15.8 \\
0 to 4 years & 21.8 \\
5 to 9 years & 22.5 \\
10 years and more & 37.0 \\
Missing values & 2.9 \\
\hline
\end{tabular}

Panel A.4 Variable: Country of work, 2009-2012

\begin{tabular}{l|r}
\hline Country of work & Observations (in \%) \\
\hline Same country & 41.6 \\
Another country & 1.2 \\
Notemployed & 57.1 \\
Missing values & 0.1 \\
\hline
\end{tabular}

Note: All four reported variable distributions are conditional on individuals not being recorded as EU citizens. Observations from Croatia are unavailable for all years; observations from Malta are not available for 2012. Country of residence one year before is always missing in observations from Finland, Ireland, Malta and the Netherlands.

Source: OECD Secretaria1t calculations based on the EU Labour Force Survey (Eurostat). 


\section{ANNEX B: REGRESSION RESULTS}

Table B.1. Estimation of a model with individual covariates, 2011/2012

- reg mobile i.treatment i.ltr i.tcnltr i.y2012 \$covariates \$cob

\begin{tabular}{|c|c|c|c|c|}
\hline Source & df & MS & Number of obs $=$ & 14644 \\
\hline Model & 81.0288301 & 3.52299261 & Prob > F & 0.00 \\
\hline Residual & 1771.91282146417 & .012101824 & R-squared & 0.04 \\
\hline Total & 1852.94165146440 & .012653248 & $\begin{array}{l}\text { Adj R-squared }= \\
\text { Root MSE }\end{array}$ & $\begin{array}{l}0.04 \\
.110\end{array}$ \\
\hline
\end{tabular}

\begin{tabular}{|c|c|c|c|c|c|c|}
\hline mobile & Coef. & Std. Err. & t & $P>|t|$ & [95\% Conf. & Interval] \\
\hline 1.treatment & -.0644616 & .0020869 & -30.89 & 0.000 & -.0685519 & -.0603713 \\
\hline 1.1 tr & -.055971 & .0011226 & -49.86 & 0.000 & -.0581712 & -.0537707 \\
\hline 1.tcnltr & .0549202 & .0014109 & 38.93 & 0.000 & .0521549 & .0576855 \\
\hline $1 . \mathrm{y} 2012$ & .0046065 & .0005766 & 7.99 & 0.000 & .0034763 & .0057367 \\
\hline ageatmig & .0003659 & .000043 & 8.51 & 0.000 & .0002816 & .0004501 \\
\hline age & .0000621 & .0000398 & 1.56 & 0.119 & -.0000159 & .0001401 \\
\hline 1. employed & .0401328 & .0266876 & 1.50 & 0.133 & -.0121743 & .0924399 \\
\hline 1. unemployed & .0007288 & .0010068 & 0.72 & 0.469 & -.0012445 & .0027022 \\
\hline 1.female & -.0020174 & .0006496 & -3.11 & 0.002 & -.0032906 & -.0007442 \\
\hline 1.highedu & .0115238 & .0008367 & 13.77 & 0.000 & .009884 & .0131637 \\
\hline 1. mededu & .0022634 & .0006708 & 3.37 & 0.001 & .0009486 & .0035782 \\
\hline 1. ftemployed & -.031787 & .0266871 & -1.19 & 0.234 & -.0840932 & .0205192 \\
\hline 1.ptemployed & -.0314898 & .0266949 & -1.18 & 0.238 & -.0838113 & .0208317 \\
\hline 1.married & .0032761 & .0007899 & 4.15 & 0.000 & .0017278 & .0048243 \\
\hline 1. childpresent & -.0096288 & .0011766 & -8.18 & 0.000 & -.0119349 & -.0073228 \\
\hline 1.bornhere & -.0062384 & .0007754 & -8.05 & 0.000 & -.0077582 & -.0047187 \\
\hline 1. othereurope & -.0019155 & .0018428 & -1.04 & 0.299 & -.0055273 & .0016963 \\
\hline 1.africa & -.0001388 & .0018787 & -0.07 & 0.941 & -.0038209 & .0035433 \\
\hline 1.middleeast & -.0012682 & .0023 & -0.55 & 0.581 & -.0057763 & .0032398 \\
\hline 1.otherasia & -.0059442 & .0020287 & -2.93 & 0.003 & -.0099205 & -.0019679 \\
\hline 1. namerica & -.0029442 & .0038146 & -0.77 & 0.440 & -.0104206 & .0045323 \\
\hline 1.samerica & -.0029728 & .0021227 & -1.40 & 0.161 & -.0071334 & .0011877 \\
\hline 1.oceania & .0040637 & .0064485 & 0.63 & 0.529 & -.0085753 & .0167026 \\
\hline cons & .0601651 & .001445 & 41.64 & 0.000 & .0573329 & .0629972 \\
\hline
\end{tabular}

Source: $\quad$ OECD Secretariat calculations based on the EU Labour Force Survey (Eurostat). 
Table B.2. Estimation of a model with individual covariates and fixed effects, 2011/2012

- reg mobile i.treatment i.ltr i.tcnltr i.y2012 \$covariates \$cob \$past \$now note: 0. nowDE omitted because of collinearity

note: 0 .nowDK omitted because of collinearity

note: 0. nowSE omitted because of collinearity

note: 1.nowUK omitted because of collinearity

\begin{tabular}{r|crc} 
Source & SS & df & MS \\
\hline $\begin{array}{r}\text { Model } \\
\text { Residual }\end{array}$ & $\begin{array}{l}720.441681 \\
966.612495113028\end{array}$ & $\begin{array}{r}.008551974 \\
.008569\end{array}$ \\
\hline Total & 1687.05418113095 & .014917142
\end{tabular}

$\begin{array}{ll}\text { Number of obs } & =113096 \\ \text { F }(67,113028) & =1257.35 \\ \text { Prob }>\text { F } & 0.0000 \\ \text { R-squared } & =0.4270 \\ \text { Adj R-squared } & =0.4267 \\ \text { Root MSE } & .09248\end{array}$

\begin{tabular}{|c|c|c|c|c|c|c|}
\hline mobile & Coef. & Std. Err. & t & $P>|t|$ & [95\% Conf. & Interval] \\
\hline 1.treatment & -.037568 & .0020455 & -18.37 & 0.000 & -.0415772 & -.0335589 \\
\hline $1.1 \mathrm{tr}$ & -.0298818 & .0012321 & -24.25 & 0.000 & -.0322966 & -.0274669 \\
\hline 1.tenltr & .0291098 & .0014536 & 20.03 & 0.000 & .0262608 & .0319588 \\
\hline $1 \cdot \mathrm{y} 2012$ & .0010503 & .00056 & 1.88 & 0.061 & -.0000473 & .0021479 \\
\hline ageatmig & .0004574 & .0000453 & 10.10 & 0.000 & .0003687 & .0005461 \\
\hline age & -.0001627 & .0000425 & -3.83 & 0.000 & -.000246 & -.0000795 \\
\hline 1. employed & .0089626 & .0224612 & 0.40 & 0.690 & -.0350611 & .0529863 \\
\hline 1. unemployed & .0024171 & .0009913 & 2.44 & 0.015 & .0004742 & .0043599 \\
\hline 1.female & -.0022946 & .0006314 & -3.63 & 0.000 & -.0035322 & -.0010571 \\
\hline 1.highedu & .0104559 & .0008711 & 12.00 & 0.000 & .0087486 & .0121632 \\
\hline 1.mededu & -.0003487 & .0006421 & -0.54 & 0.587 & -.0016073 & .0009099 \\
\hline 1.ftemployed & .0003212 & .0224604 & 0.01 & 0.989 & -.0437008 & .0443433 \\
\hline 1.ptemployed & .0015593 & .022469 & 0.07 & 0.945 & -.0424796 & .0455982 \\
\hline 1.married & .0027357 & .0007859 & 3.48 & 0.000 & .0011954 & .004276 \\
\hline 1. childpresent & -.0087308 & .0011623 & -7.51 & 0.000 & -.0110089 & -.0064528 \\
\hline 1.bornhere & -.0007889 & .0007476 & -1.06 & 0.291 & -.0022542 & .0006764 \\
\hline 1. othereurope & -.0063991 & .0017302 & -3.70 & 0.000 & -.0097903 & -.0030079 \\
\hline 1.africa & -.0059598 & .0017897 & -3.33 & 0.001 & -.0094676 & -.0024519 \\
\hline 1.middleeast & -.0033139 & .0021792 & -1.52 & 0.128 & -.0075851 & .0009573 \\
\hline 1. otherasia & -.0059735 & .0019354 & -3.09 & 0.002 & -.0097669 & -.0021801 \\
\hline 1. namerica & -.0160944 & .0038885 & -4.14 & 0.000 & -.0237159 & -.008473 \\
\hline 1. samerica & -.0040575 & .0019963 & -2.03 & 0.042 & -.0079703 & -.0001447 \\
\hline 1.oceania & -.001758 & .0067486 & -0.26 & 0.794 & -.0149851 & .0114691 \\
\hline
\end{tabular}

Note: $\quad$ The variable Itr equals 1 for five and more years of residence in the same EU country, otherwise 0.

Source: OECD Secretariat calculations based on the EU Labour Force Survey (Eurostat). 
Table B.3. Estimation of a model with individual covariates and clustered S.E.s, 2011/2012

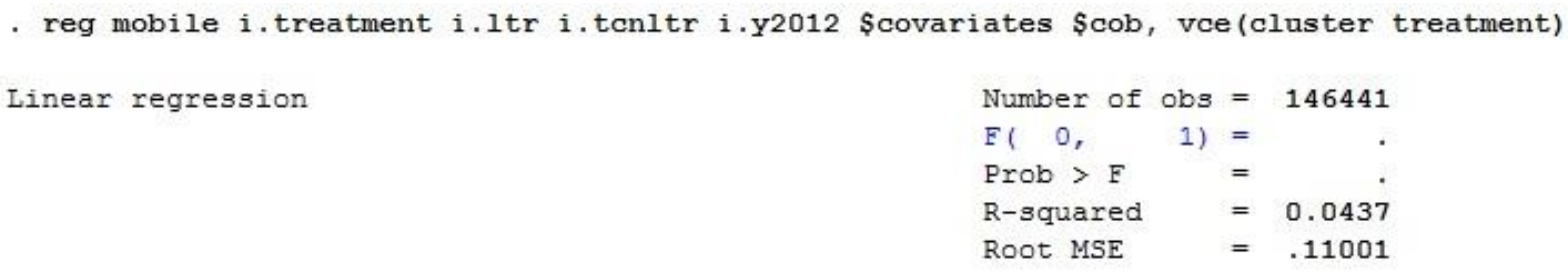

(Std. Err. adjusted for 2 clusters in treatment)

\begin{tabular}{|c|c|c|c|c|c|c|}
\hline \multirow[b]{2}{*}{ mobile } & \multicolumn{3}{|c|}{ Robust } & \multirow[b]{2}{*}{$P>|t|$} & \multirow[b]{2}{*}{ [95\% Conf. } & \multirow[b]{2}{*}{ Interval] } \\
\hline & Coef. & Std. Err. & $t$ & & & \\
\hline 1.treatment & -.0644616 & .0019218 & -33.54 & 0.019 & -.0888808 & -.0400424 \\
\hline 1.1 tr & -.055971 & .0036449 & -15.36 & 0.041 & -.1022837 & -.0096583 \\
\hline 1.tcnltr & .0549202 & .0000706 & 778.34 & 0.001 & .0540236 & .0558168 \\
\hline $1 \cdot \mathrm{y} 2012$ & .0046065 & .005285 & 0.87 & 0.544 & -.0625461 & .0717591 \\
\hline ageatmig & .0003659 & .0004556 & 0.80 & 0.569 & -.0054225 & .0061542 \\
\hline age & .0000621 & .0000784 & 0.79 & 0.574 & -.0009344 & .0010585 \\
\hline 1. employed & .0401328 & .0270856 & 1.48 & 0.378 & -.3040223 & .3842879 \\
\hline 1. unemployed & .0007288 & .0002179 & 3.34 & 0.185 & -.0020401 & .0034978 \\
\hline 1. female & -.0020174 & .0018185 & -1.11 & 0.467 & -.0251243 & .0210894 \\
\hline 1. highedu & .0115238 & .0097111 & 1.19 & 0.446 & -.1118676 & .1349152 \\
\hline 1. mededu & .0022634 & .0028393 & 0.80 & 0.572 & -.0338136 & .0383403 \\
\hline 1. ftemployed & -.031787 & .018517 & -1.72 & 0.336 & -.2670679 & .2034939 \\
\hline 1.ptemployed & -.0314898 & .0177933 & -1.77 & 0.327 & -.2575755 & .1945958 \\
\hline 1.married & .0032761 & .0023266 & 1.41 & 0.393 & -.0262867 & .0328388 \\
\hline 1. childpresent & -.0096288 & .0109808 & -0.88 & 0.542 & -.1491537 & .1298961 \\
\hline 1.bornhere & -.0062384 & .0062944 & -0.99 & 0.503 & -.0862161 & .0737392 \\
\hline 1. othereurope & -.0019155 & .0008844 & -2.17 & 0.275 & -.013153 & .009322 \\
\hline 1.africa & -.0001388 & .0033105 & -0.04 & 0.973 & -.0422026 & .041925 \\
\hline 1.middleeast & -.0012682 & .0044108 & -0.29 & 0.822 & -.0573123 & .0547759 \\
\hline 1.otherasia & -.0059442 & .0015511 & -3.83 & 0.162 & -.0256532 & .0137647 \\
\hline 1. namerica & -.0029442 & .0003619 & -8.14 & 0.078 & -.0075421 & .0016537 \\
\hline 1. samerica & -.0029728 & .0012439 & -2.39 & 0.252 & -.0187781 & .0128324 \\
\hline 1.oceania & .0040637 & .0118464 & 0.34 & 0.790 & -.146459 & .1545864 \\
\hline _cons & .0601651 & .0158997 & 3.78 & 0.164 & -.1418596 & .2621898 \\
\hline
\end{tabular}

Note: $\quad$ The variable Itr equals 1 for five and more years of residence in the same EU country, otherwise 0.

Source: $\quad$ OECD Secretariat calculations based on the EU Labour Force Survey (Eurostat). 
Table B.4: Estimation of a model with individual covariates, 2011/2012

- reg mobile i.treatment i.y2012 i.MMS2012 \$covariates \$cob

\begin{tabular}{r|rrr} 
Source & \multicolumn{1}{|c}{ SS } & df & MS \\
\hline Model & .31881609 & 22 & .01449164 \\
Residual & 71.5807013 & 51568 & .001388084 \\
\hline Total & 71.8995174 & 51590 & .001393672
\end{tabular}

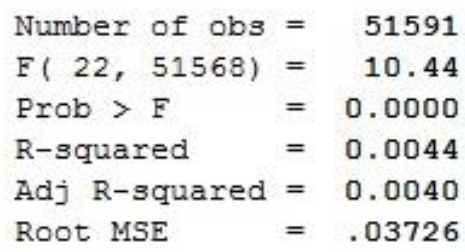

\begin{tabular}{r|rrrrrr}
\hline mobile & Coef. & Std. Err. & $t$ & P $>$ t t & [95\% Conf. Interval] \\
\hline 1.treatment & -.0004593 & .0018945 & -0.24 & 0.808 & -.0041725 & .0032539 \\
1.y2012 & .0001105 & .0003889 & 0.28 & 0.776 & -.0006517 & .0008728 \\
1.NMS2012 & .0029617 & .0007284 & 4.07 & 0.000 & .001534 & .0043894 \\
ageatmig & .000088 & .0000246 & 3.58 & 0.000 & .0000398 & .0001362 \\
age & -.0000573 & .0000224 & -2.56 & 0.011 & -.0001012 & -.0000134 \\
1.employed & -.0020561 & .014089 & -0.15 & 0.884 & -.0296706 & .0255584 \\
1.unemployed & -.0004631 & .0005613 & -0.83 & 0.409 & -.0015632 & .000637 \\
1.female & .0003253 & .0003766 & 0.86 & 0.388 & -.0004128 & .0010634 \\
1.highedu & .0018335 & .0005258 & 3.49 & 0.000 & .0008029 & .0028641 \\
1.mededu & .0008109 & .000369 & 2.20 & 0.028 & .0000876 & .0015342 \\
1.ftemployed & .0029064 & .014087 & 0.21 & 0.837 & -.0247042 & .0305171 \\
1.ptemployed & .0034498 & .0140932 & 0.24 & 0.807 & -.024173 & .0310727 \\
1.married & -.0004435 & .0004854 & -0.91 & 0.361 & -.0013949 & .0005079 \\
1.childpresent & -.0011712 & .0007097 & -1.65 & 0.099 & -.0025623 & .0002199 \\
1.bornhere & -.0021729 & .0004294 & -5.06 & 0.000 & -.0030146 & -.0013312 \\
1.0thereurope & -.0013484 & .0018374 & -0.73 & 0.463 & -.0049497 & .002253 \\
1.africa & -.004098 & .0090726 & -0.45 & 0.651 & -.0218803 & .0136843 \\
1.middleeast & -.0017132 & .0030483 & -0.56 & 0.574 & -.0076879 & .0042616 \\
1.0therasia & -.0014303 & .0087249 & -0.16 & 0.870 & -.0185312 & .0156706 \\
1.namerica & -.0060502 & .0186374 & -0.32 & 0.745 & -.0425797 & .0304792 \\
1.samerica & -.0032076 & .0125607 & -0.26 & 0.798 & -.0278267 & .0214115 \\
1.oceania & -.0065573 & .0166739 & -0.39 & 0.694 & -.0392383 & .0261238 \\
_cons & .0036143 & .0019559 & 1.85 & 0.065 & -.0002194 & .0074479 \\
\hline & & & & & &
\end{tabular}

Note:

The variable y2012 equals 1 for observations from 2012 and 0 otherwise.

Source: OECD Secretariat calculations based on the EU Labour Force Survey (Eurostat). 
Table B.5: Estimation of a model with individual covariates and fixed effects, 2011/2012

- reg mobile i.treatment i.y2012 i.NMS2012 \$covariates \$cob \$past \$now note: 0.pastDK omitted because of collinearity note: 0 .pastSE omitted because of collinearity note: 1.nowBG omitted because of collinearity note: 0. nowDE omitted because of collinearity note: 0 .nowDK omitted because of collinearity note: 1.nowNL omitted because of collinearity note: 0. nowSE omitted because of collinearity note: 1 .nowUK omitted because of collinearity

\begin{tabular}{r|rrc} 
Source & SS & df & MS \\
\hline Model & 38.5515548 & 62 & .621799271 \\
Residual & 33.3179579 & 39665 & .000839984 \\
\hline Total & 71.8695127 & 39727 & .001809085
\end{tabular}

$\begin{array}{lr}\text { Number of obs } & =39728 \\ \text { F }(62,39665) & =740.25 \\ \text { Prob }>\text { F } & 0.0000 \\ \text { R-squared } & =0.5364 \\ \text { Adj R-squared } & =0.5357 \\ \text { Root MSE } & =.02898\end{array}$

\begin{tabular}{r|rrrrrr}
\hline mobile & Coef. & Std. Err. & $t$ & P $>|t|$ & [95\% Conf. Interval] \\
\hline 1.treatment & -.0023258 & .0016532 & -1.41 & 0.159 & -.005566 & .0009145 \\
1.y2012 & -.0002467 & .0003139 & -0.79 & 0.432 & -.0008619 & .0003685 \\
1.NMS2012 & .0055838 & .0008797 & 6.35 & 0.000 & .0038595 & .0073081 \\
ageatmig & .000051 & .0000242 & 2.11 & 0.035 & $3.52 e-06$ & .0000985 \\
age & -.0000439 & .0000223 & -1.97 & 0.049 & -.0000877 & $-1.59 e-07$ \\
1.employed & -.0084378 & .0109945 & -0.77 & 0.443 & -.0299873 & .0131117 \\
1.unemployed & .0004528 & .0005151 & 0.88 & 0.379 & -.0005568 & .0014624 \\
1.female & -.0000583 & .0003411 & -0.17 & 0.864 & -.0007268 & .0006102 \\
1.highedu & .0013002 & .0005326 & 2.44 & 0.015 & .0002562 & .0023442 \\
1.mededu & .000451 & .0003305 & 1.36 & 0.172 & -.0001968 & .0010988 \\
1.ftemployed & .0094197 & .0109925 & 0.86 & 0.391 & -.0121259 & .0309654 \\
1.ptemployed & .0098114 & .0109994 & 0.89 & 0.372 & -.0117477 & .0313705 \\
1.married & .0000171 & .0004726 & 0.04 & 0.971 & -.0009092 & .0009435 \\
1.childpresent & -.000831 & .0006926 & -1.20 & 0.230 & -.0021884 & .0005264 \\
1.bornhere & -.0011816 & .0003997 & -2.96 & 0.003 & -.001965 & -.0003981 \\
1.othereurope & -.0022904 & .001538 & -1.49 & 0.136 & -.0053049 & .000724 \\
1.africa & -.0040477 & .0080711 & -0.50 & 0.616 & -.0198673 & .0117719 \\
1.middleeast & -.0028208 & .0025115 & -1.12 & 0.261 & -.0077434 & .0021019 \\
1.otherasia & -.0019374 & .0081709 & -0.24 & 0.813 & -.0179525 & .0140777 \\
1.namerica & -.0753594 & .0146685 & -5.14 & 0.000 & -.1041099 & -.0466089 \\
1.samerica & -.0030331 & .0168255 & -0.18 & 0.857 & -.0360115 & .0299452 \\
1.oceania & -.0075086 & .012987 & -0.58 & 0.563 & -.0329634 & .0179462
\end{tabular}

Note: $\quad$ The variable $y 2012$ equals 1 for observations from 2012 and 0 otherwise.

Source: OECD Secretariat calculations based on the EU Labour Force Survey (Eurostat). 
Table B.6. Estimation of a model with individual covariates, 2011/2012

. reg mobile i.treatment i.y2012 i.MMS2012 \$covariates \$cob

\begin{tabular}{|c|c|c|c|c|c|c|}
\hline Source & ss & df & MS & Number of obs & $=$ & 302 \\
\hline Model & .6233705 & 22 & .028335023 & $\mathrm{Prob}>\mathrm{F}$ & $=$ & 0.00 \\
\hline Residual & 100.039429 & 30229 & .003309386 & R-squared & $=$ & \\
\hline otal & 100.662799 & 30251 & 003327586 & $\begin{array}{l}\text { Adj R-squared } \\
\text { Root MSE }\end{array}$ & $\begin{array}{l}= \\
=\end{array}$ & \\
\hline
\end{tabular}

\begin{tabular}{|c|c|c|c|c|c|c|}
\hline mobile & Coef. & Std. Err. & t & $P>|t|$ & [95\% Conf. & Interval] \\
\hline 1.treatment & -.0016664 & .0009899 & -1.68 & 0.092 & -.0036066 & .0002739 \\
\hline $1 . \mathrm{y} 2012$ & .0007699 & .0009258 & 0.83 & 0.406 & -.0010448 & .0025846 \\
\hline 1. NMS2012 & .0026174 & .001327 & 1.97 & 0.049 & .0000164 & .0052185 \\
\hline ageatmig & .0007585 & .0000753 & 10.08 & 0.000 & .000611 & .000906 \\
\hline age & -.0006724 & .0000748 & -8.99 & 0.000 & -.0008191 & -.0005258 \\
\hline 1. employed & -.0044716 & .0257478 & -0.17 & 0.862 & -.0549383 & .0459951 \\
\hline 1. unemployed & -.0021433 & .0011561 & -1.85 & 0.064 & -.0044094 & .0001228 \\
\hline 1. female & -.0000206 & .0007536 & -0.03 & 0.978 & -.0014977 & .0014565 \\
\hline 1. highedu & .0034815 & .0010462 & 3.33 & 0.001 & .001431 & .0055321 \\
\hline 1. mededu & .0020052 & .0007723 & 2.60 & 0.009 & .0004913 & .003519 \\
\hline 1.ftemployed & .0037032 & .0257394 & 0.14 & 0.886 & -.0467472 & .0541536 \\
\hline 1.ptemployed & .0060974 & .0257537 & 0.24 & 0.813 & -.044381 & .0565758 \\
\hline 1.married & -.0002437 & .0008397 & -0.29 & 0.772 & -.0018895 & .001402 \\
\hline 1. childpresent & -.0027482 & .0012584 & -2.18 & 0.029 & -.0052147 & -.0002818 \\
\hline 1.bornhere & -.0020729 & .0007858 & -2.64 & 0.008 & -.0036132 & -.0005326 \\
\hline 1.othereurope & .002415 & .0020778 & 1.16 & 0.245 & -.0016575 & .0064876 \\
\hline 1.africa & -.0056577 & .0182059 & -0.31 & 0.756 & -.0413419 & .0300266 \\
\hline 1.middleeast & -.0065895 & .018205 & -0.36 & 0.717 & -.042272 & .029093 \\
\hline 1.otherasia & -.0092903 & .0575416 & -0.16 & 0.872 & -.1220742 & .1034937 \\
\hline 1. namerica & -.0088197 & .0287835 & -0.31 & 0.759 & -.0652367 & .0475972 \\
\hline 1.samerica & .0006263 & .0575432 & 0.01 & 0.991 & -.1121608 & .1134135 \\
\hline 1.oceania & -.007155 & .0257529 & -0.28 & 0.781 & -.0576317 & .0433217 \\
\hline _cons & .0088085 & .0015489 & 5.69 & 0.000 & .0057726 & .0118443 \\
\hline
\end{tabular}

Note: $\quad$ The variable $y 2012$ equals 1 for observations from 2012 and 0 otherwise.

Source: OECD Secretariat calculations based on the EU Labour Force Survey (Eurostat). 
Table B.7. Estimation of a model with individual covariates and fixed effects, 2011/2012

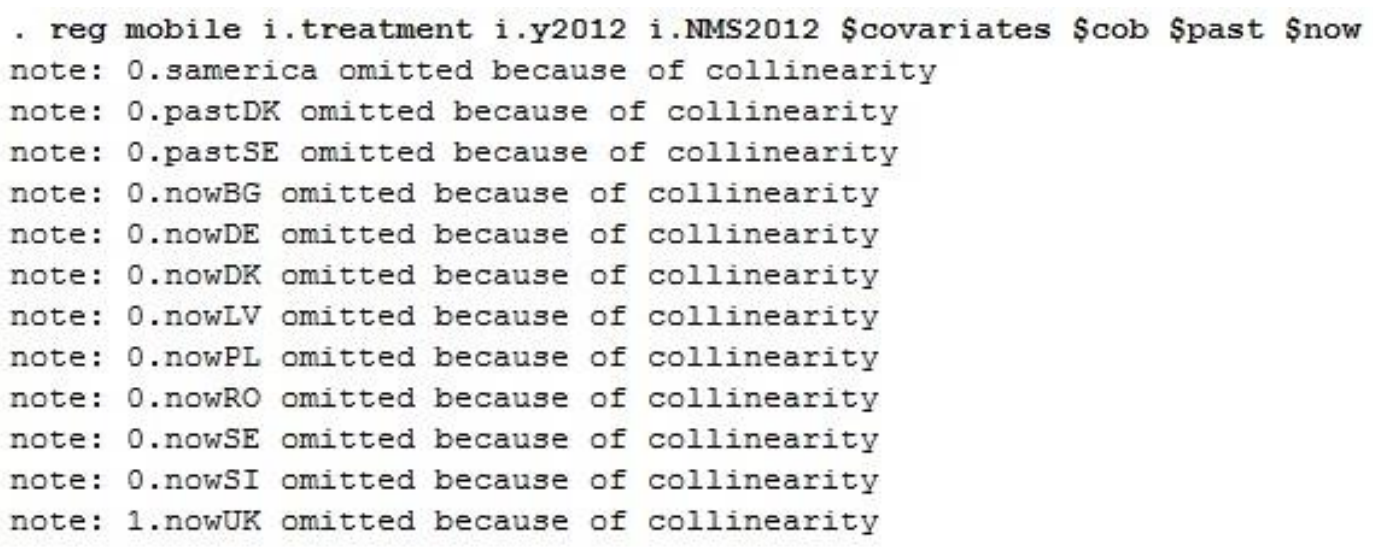

\begin{tabular}{r|rrc} 
Source & SS & df & MS \\
\hline Model & 83.1475605 & 58 & 1.43357863 \\
Residual & 17.332961 & 19578 & .000885328 \\
\hline Total & 100.480521 & 19636 & .005117158
\end{tabular}

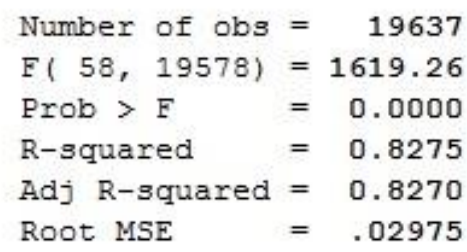

\begin{tabular}{|c|c|c|c|c|c|c|}
\hline mobile & Coef. & Std. Err. & t & $P>|t|$ & [95응 Conf. & Interval] \\
\hline 1.treatment & -.0011956 & .0007995 & -1.50 & 0.135 & -.0027628 & .0003715 \\
\hline 1. $\mathrm{y} 2012$ & -.0000697 & .0004972 & -0.14 & 0.889 & -.0010443 & .0009049 \\
\hline 1. NMS2012 & .0025659 & .0009797 & 2.62 & 0.009 & .0006456 & .0044861 \\
\hline ageatmig & .0000411 & .0000467 & 0.88 & 0.380 & -.0000505 & .0001327 \\
\hline age & -.0000621 & .0000457 & -1.36 & 0.174 & -.0001517 & .0000275 \\
\hline 1. employed & -.0007679 & .0133754 & -0.06 & 0.954 & -.0269848 & .025449 \\
\hline 1. unemployed & .0006319 & .0007956 & 0.79 & 0.427 & -.0009275 & .0021913 \\
\hline 1. female & .0001246 & .0005003 & 0.25 & 0.803 & -.000856 & .0011052 \\
\hline 1. highedu & .0023523 & .0007659 & 3.07 & 0.002 & .0008512 & .0038535 \\
\hline 1.mededu & -.000091 & .0005064 & -0.18 & 0.857 & -.0010835 & .0009016 \\
\hline 1.ftemployed & .0015609 & .0133675 & 0.12 & 0.907 & -.0246407 & .0277624 \\
\hline 1.ptemployed & .0032466 & .0133797 & 0.24 & 0.808 & -.0229788 & .029472 \\
\hline 1.married & .0010252 & .0005695 & 1.80 & 0.072 & -.000091 & .0021413 \\
\hline 1. childpresent & -.0003142 & .0008847 & -0.36 & 0.723 & -.0020483 & .00142 \\
\hline 1.bornhere & -.0001159 & .0005212 & -0.22 & 0.824 & -.0011375 & .0009057 \\
\hline 1. othereurope & -.0026929 & .0012024 & -2.24 & 0.025 & -.0050498 & -.000336 \\
\hline 1.africa & -.0057211 & .0105443 & -0.54 & 0.587 & -.0263888 & .0149467 \\
\hline 1.middleeast & .0003496 & .0148954 & 0.02 & 0.981 & -.0288467 & .0295458 \\
\hline 1.otherasia & -.0077561 & .0298132 & -0.26 & 0.795 & -.0661924 & .0506802 \\
\hline 1. namerica & -.1898264 & .0153769 & -12.34 & 0.000 & -.2199666 & -.1596863 \\
\hline 0. samerica & 0 & (omitted) & & & & \\
\hline 1.oceania & -.0082881 & .0133436 & -0.62 & 0.535 & -.0344427 & .0178666 \\
\hline
\end{tabular}

Note: $\quad$ The variable y2012 equals 1 for observations from 2012 and 0 otherwise.

Source: OECD Secretariat calculations based on the EU Labour Force Survey (Eurostat). 
DELSA/ELSA/WD/SEM(2016)13

\section{ANNEX C: ADDITIONAL TABLES AND FIGURES}

Table C.1. Highly educated third-country nationals by group of nationalities, 2008-2012 in thousands

\begin{tabular}{lrrrrr}
\hline Group of nationalities & 2008 & 2009 & 2010 & 2011 & 2012 \\
\hline EFTA countries & 62 & 92 & 68 & 78 & 68 \\
Europe without EU/EFTA & 604 & 629 & 606 & 733 & 768 \\
Africa & 540 & 551 & 607 & 695 & 703 \\
Near Middle East & 169 & 183 & 153 & 177 & 193 \\
Other Asia & 566 & 519 & 576 & 760 & 836 \\
North America & 187 & 209 & 225 & 276 & 258 \\
South and Central America & 457 & 502 & 430 & 498 & 523 \\
Australia and Oceania & 102 & 93 & 72 & 111 & 90 \\
\hline Total & 2687 & 2779 & 2738 & 3328 & 3440 \\
\hline
\end{tabular}

Note: The geographical delimitation is adopted from Eurostat.

Source: EU Labour Force Survey (Eurostat). 
DELSA/ELSA/WD/SEM(2016)13

Figure C1. Coverage of long-term resident permits by EU member state, 2012

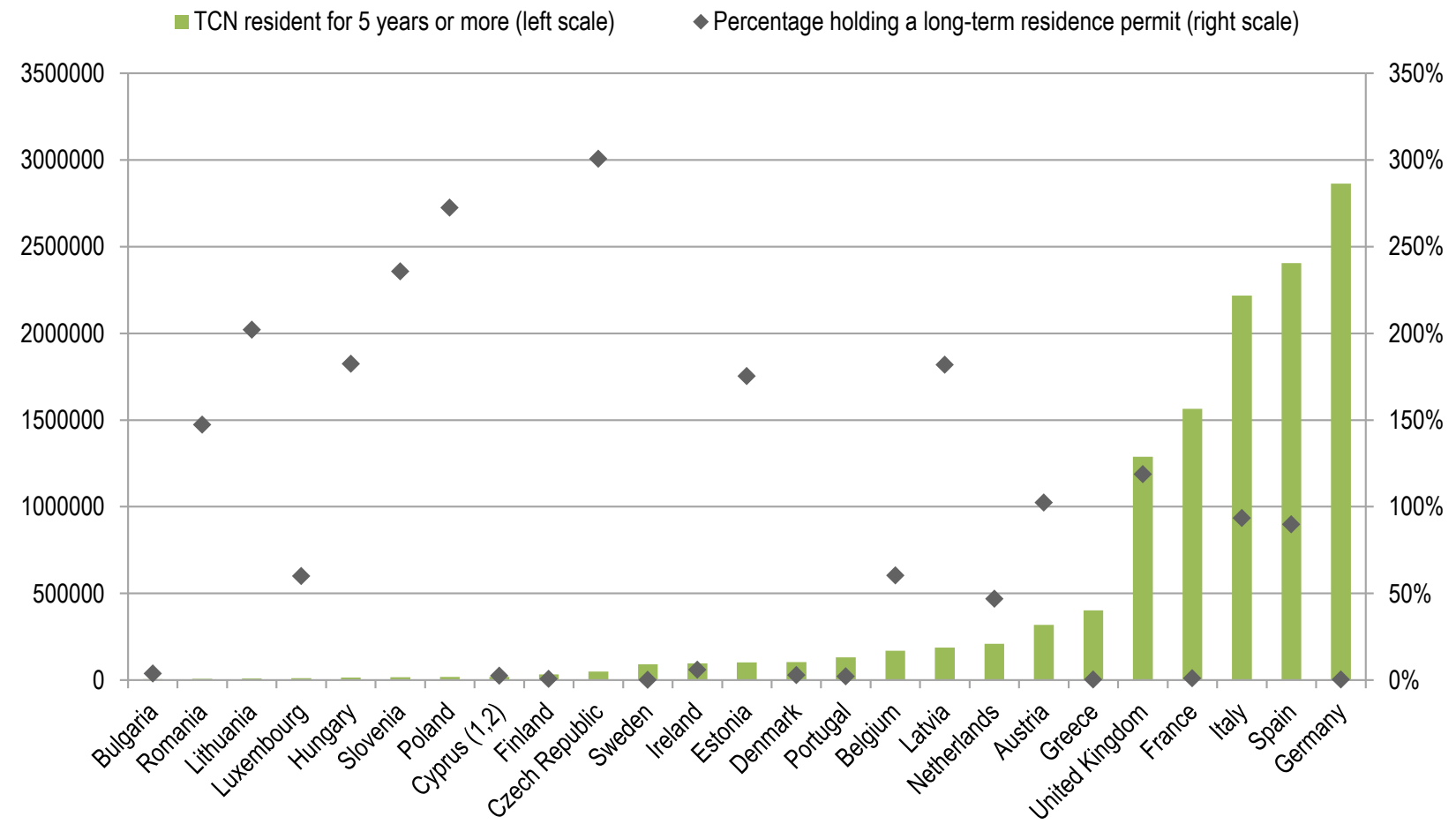

Note: $\quad 1$ ) Note by Turkey: The information in this document with reference to "Cyprus" relates to the southern part of the Island There is no single authority representing both Turkish and Greek Cypriot people on the Island. Turkey recognises the Turkish Republic of Northern Cyprus (TRNC). Until a lasting and equitable solution is found within the context of the United Nations, Turkey shall preserve its position concerning the "Cyprus issue".

2) Note by all the European Union Member States of the OECD and the European Union: The Republic of Cyprus is recognised by all members of the United Nations with the exception of Turkey. The information in this document relates to the area under the effective control of the Government of the Republic of Cyprus.

Source: OECD Secretariat calculations based on residence permit data and the EU Labour Force Survey (both Eurostat). 
Figure C.2. Number of long-term residence permits by issuing EU member state, 2012

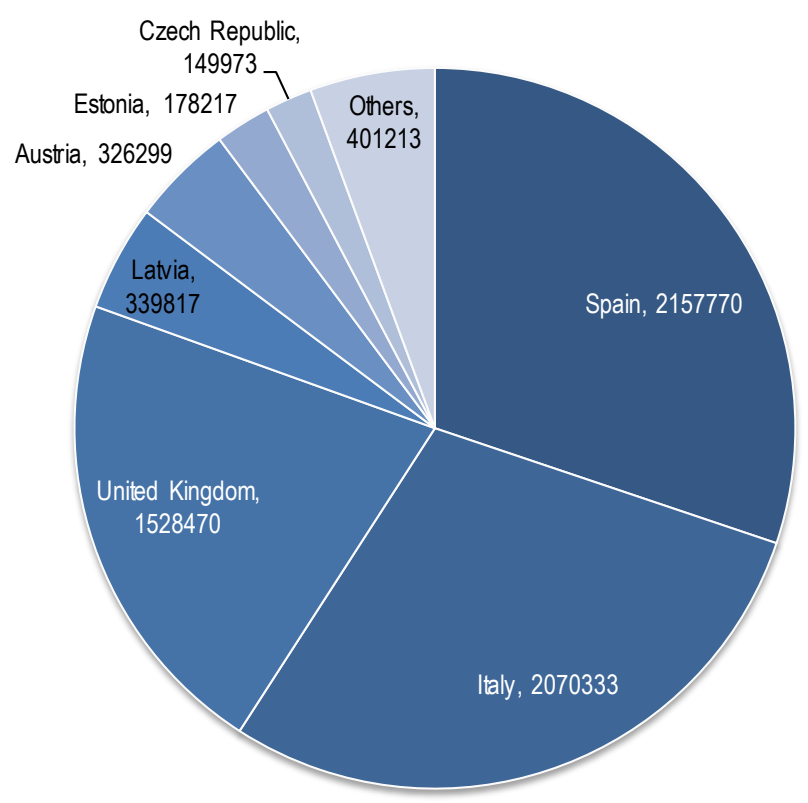

Source: Eurostat residence permit (Resper) data collection.

Table C.2. TCN who are eligible for long-term residence by group of nationality, 2008-2012 in thousands

\begin{tabular}{lrrrrr}
\hline Group of nationalities & 2008 & 2009 & 2010 & 2011 & 2012 \\
\hline EFTAcountries & 101 & 114 & 128 & 120 & 112 \\
Europe without EU/EFTA & 3827 & 3998 & 4205 & 4346 & 4447 \\
Africa & 2810 & 2966 & 3217 & 3208 & 3460 \\
Near Middle East & 459 & 513 & 453 & 457 & 500 \\
Other Asia & 1410 & 1388 & 1480 & 1587 & 1767 \\
North America & 226 & 226 & 271 & 239 & 256 \\
South and Central America & 1776 & 1963 & 1872 & 1991 & 1835 \\
Australia and Oceania & 117 & 106 & 98 & 102 & 84 \\
\hline Total & 10534 & 11085 & 11483 & 11842 & 12245 \\
\hline
\end{tabular}

Note: The geographical delimitation is adopted from Eurostat.

Source: EU Labour Force Survey (Eurostat). 